\title{
Heparin promotes fibrillation of most phenol soluble modulin peptides from $S$. aureus: a possible strengthening of the bacterial biofilm
}

\author{
Zahra Najarzadeh $^{1}$, Masihuz Zaman ${ }^{2 \#}$, Vita Serekaité ${ }^{3}$, Kristian Strømgaard ${ }^{3}$, Maria Andreasen ${ }^{2 *}$ \\ and Daniel E. Otzen ${ }^{1 *}$
}

${ }^{1}$ Interdisciplinary Nanoscience Centre (iNANO), Aarhus University, Gustav Wieds Vej 14, 8000 Aarhus C, Denmark

${ }^{2}$ Aarhus University, Department of Biomedicine, Wilhelm Meyers Allé 3, 8000 Aarhus C,

Denmark

${ }^{3}$ Department of Drug Design and Pharmacology, University of Copenhagen, 2100 Copenhagen $\emptyset$, Denmark

*To whom correspondence should be addressed at mariaj@biomed.au.dk and dao@inano.au.dk.

${ }^{\#}$ Equal contributors.

Keywords: Phenol soluble modulin, bacterial amyloid, Heparin, PSM peptides, Biofilm, Staphylococcus aureus.

Running title: Effect of heparin on aggregation of S. aureus PSMs. 
bioRxiv preprint doi: https://doi.org/10.1101/2021.03 07.434294: this version posted March 9 2021. The copyright holder for this preprint (which was not certified by peer review) is the author/funder, who has granted bioRxiv a license to display the preprint in perpetuity. It is made available under aCC-BY-NC-ND 4.0 International license.

\begin{abstract}
Phenol soluble modulins (PSMs) are virulence peptides secreted by different Staphylococcus aureus strains. In addition, PSMs are able to form amyloid fibrils which may strengthen the biofilm matrix. The highly sulfated glycosaminoglycan heparin promotes S.aureus infection but the basis for this is unclear. We hypothesized that heparin promotes PSM fibrillation and in this way aids bacterial colonization. Here we address this hypothesis using a combination of different biophysical techniques along with peptide microarrays. We find that heparin accelerates fibrillation of all $\alpha$ PSMs (except PSM $\alpha 2$ ) and $\delta$-toxin, but inhibits $\beta$-PSMs' fibrillation by blocking nucleation. Given that $S$. aureus secretes higher levels of $\alpha$-PSMs than $\beta$-PSMs peptidess, heparin is likely to overall promote fibrillation. Heparin binding is driven by multiple positively charged lysine residues in $\alpha$ PSMs and $\delta$-toxins, whose removal strongly reduces affinity. Binding of heparin does not alter the final fibril conformation. Rather, heparin provides a scaffold to catalyze or inhibit fibrillation. Our findings suggest that heparin may strengthen bacterial biofilm through increased PSM fibrillation.
\end{abstract}

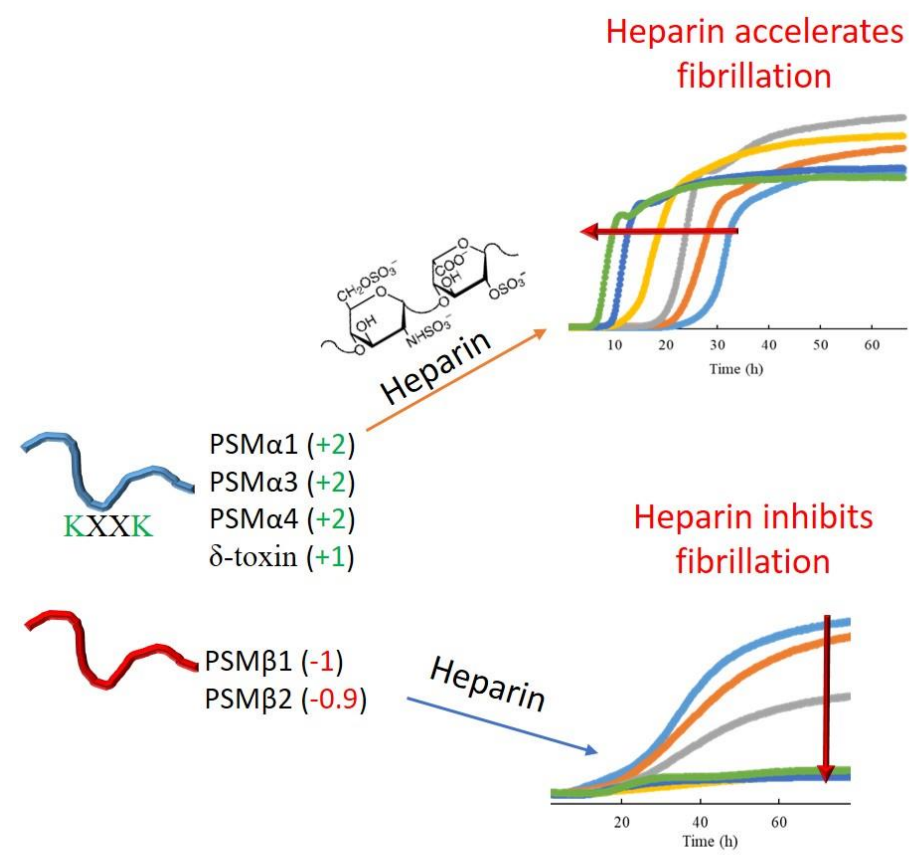

Schematic representation of effect of heparin on fibrillation of different PSMs. The numbers in brackets are the net charge of peptides at $\mathrm{pH} 7$. 


\section{INTRODUCTION}

Functional bacterial amyloids are proteins secreted from bacteria which self-assemble to form highly ordered $\beta$-sheet-rich fibrils or amyloids. These fibrils promote bacterial biofilm formation by acting as structural scaffolds in the biofilm matrix, leading to increased antibiotic resistance [1]. The most well-understood functional bacterial amyloids are curli in Escherichia coli [2], Fap in Pseudomonas [3], TasA in Bacillus subtilis [4] and phenol-soluble modulins (PSMs) in Staphylococcus strains [5]. Unlike the other amyloids, PSMs are short peptides with multiple functions. Besides their ability to strengthen biofilm through amyloid formation, they act as virulence factors which lyse neutrophils and erythrocytes and stimulate inflammatory responses [68]. As amphipathic peptides they are both surface- and membrane-active and this is thought to lead to cell permeabilization, as well as encouraging early steps in biofilm formation [5, 9]. PSMs are classified according to their length: the shortest (20-25 residues) and most abundant are the four $\alpha$ PSMs and $\delta$-toxin which all adopt an $\alpha$-helical amphipathic structure in solution. The two $\beta$-PSMs ( 44 residues), both containing a C-terminal amphipathic $\alpha$-helix, are found in much lower amounts in vivo [10].

Extracellular fibrils isolated from S. aureus biofilm contain several different PSMs [5]. Almost all individual PSMs fibrillate in the classic cross- $\beta$ amyloid motif with $\beta$-strands perpendicular to the fibril axis. The only exceptions are PSM $\alpha 2$ and $\delta$-toxin, which do not fibrillate on their own, and PSM $\alpha 3$, which is the first reported example of the cross- $\alpha$ fold, in which monomeric $\alpha$-helices are oriented perpendicularly to the fibril axis $[9,11]$. Preformed PSMs fibrils (particulary those formed by PSM $\alpha 1$ ) accelerate fibrillation of other PSM peptides and even seed fibrillation of PSM $\alpha 2$ and $\delta$ toxin [11]. PSM $\alpha 3$ fibrillates very rapidly and thus provides seeds to promote fibrillation of PSMs such as PSM $\alpha 1$ (despite the difference in structure) which in turn is very efficient at accelerating the fibrillation of other PSMs [11]. 
bioRxiv preprint doi: https://doi.org/10.1101/2021.03.07.434294; this version posted March 9,2021 . The copyright holder for this preprint (which was not certified by peer review) is the author/funder, who has granted bioRxiv a license to display the preprint in perpetuity. It is made available under aCC-BY-NC-ND 4.0 International license.

Besides inter-PSM interactions, other components found in the biofilm matrix such as polysaccharides, proteins and extracellular DNA (eDNA) may influence fibrillation. eDNA is known to promote PSM $\alpha 1$ fibrillation [12]; similarly, bacterial biosurfactants such as rhamnolipids and outer-membrane lipopolysaccharides generally promote amyloid formation [13]. Importantly, eukaryotic host factors can also play a role. Chief among these is heparin, a glycosaminoglycan which thanks to its many sulfate and carboxyl groups is the most highly anionic biomacromolecule known [14]. Heparin is normally stored intracellularly in secretory granules and released upon tissue injury to act as an anticoagulant, preventing clot formation by fibrinogen $[15,16]$. This has inspired its use as an anticoagulant in patient catheters, especially for kidney dialysis. In a bacterial context, however, heparin stimulates $S$. aureus biofilm formation by accumulating in the biofilm matrix, probably by binding to cell-surface proteins as a mimic of extracellular DNA. This often leads to catheter infections [17-19]. In vitro heparin effectively induces fibrillation of a range of amyloidogenic proteins e.g lysozyme, $\alpha$-synuclein, transthyretin, $\beta_{2}$-microglobulin, $A \beta$ and the prion protein [20-24]. These observations prompted us to hypothesize that heparin might encourage biofilm formation through PSM fibrillation. Here we investigate how heparin affects PSM fibrillation processes by a combination of biophysical techniques, peptide arrays and biofilm formation assays. 


\section{MATERIALS AND METHODS}

Peptides, reagents and solutions: The peptides PSM $\alpha 1$ (MGIIAGIIKVIKSLIEQFTGK), PSM $\alpha 2$ (MGIIAGIIKFIKGLIEKFTGK), PSM $\alpha 3 \quad$ (MEFVAKLFKFFKDLLGKFLGNN), PSM $\alpha 4$ (MAIVGTIIKIIKAIIDIFAK), PSM $\beta 1 \quad$ (MEGLFNAIKD TVTAAINNDG AKLGTSIVSI VENGVGLLGK LFGF), PSM $\quad$ (MTGLAEAIAN TVQAAQQHDS VKLGTSIVDI VANGVGLLGK LFGF) and $\delta$-toxin (MAQDIISTIG DLVKWIIDTV NKFTKK) were purchased from GenScript Biotech, Netherlands. All peptides were N-terminally formylated with a purity of $>95 \%$. All reagents and chemicals were of analytical grade. Heparin-fluorescein conjugate, and chemicals including Hexafluoroisopropanol (HFIP), Thioflavin T, trifluoroacetic acid (TFA) and crystal violet solution (2.3\%) were from Sigma-Aldrich Ltd. Heparin (Cat \# Y0001282) was from European Pharmacopoeia, Europe. Dimethyl-sulfoxide (DMSO) was from Merck. Peptide stock solutions were filtered using PVDF $0.22 \mu \mathrm{m}$ syringe filters (Millipore Milex-HV) before use.

Peptide pre-treatment: For aggregation kinetics and secondary structure analysis (CD and FTIR), each PSM peptide stock was pretreated to disassemble any pre-formed aggregates. All seven dry lyophilized peptides (PSM $\alpha 1-4, \operatorname{PSM} \beta 1-2$ and $\delta$-toxin) were freshly dissolved to a final concentration of $0.5 \mathrm{mg} / \mathrm{mL}$ in HFIP:TFA $(1: 1 \mathrm{v} / \mathrm{v})$ and sonicated for $5 \times 20$ seconds with 30 seconds intervals using a probe sonicator, followed by incubation at room temperature for $1 \mathrm{~h}$. Solutions were then aliquoted out and organic solvent was evaporated using a speedvac (1000 rpm for 3-4 h) at room temperature. Dried peptide stocks were stored at $-80{ }^{\circ} \mathrm{C}$ prior to use.

Thioflavin T (ThT) Fibrillation Assay: $10 \mathrm{mg}$ of heparin was dissolved in $1 \mathrm{~mL}$ milliQ water and passed through a PVDF $0.45 \mu \mathrm{m}$ syringe filter. PSMs were thawed and dissolved in dimethyl sulfoxide (DMSO) to $10 \mathrm{mg} / \mathrm{mL}$ prior to use. All seven freshly prepared peptides were diluted (typically to $0.25-1 \mathrm{mg} / \mathrm{mL}$ ) into sterile milliQ water containing $40 \mu \mathrm{M}$ ThT with $0-1 \mathrm{mg} / \mathrm{mL}$ 
heparin in a final volume of $100 \mu \mathrm{l}$ in a 96 well black polystyrene microtiter plates. Different PSMs with a fixed monomeric peptide concentration $(0.25 \mathrm{mg} / \mathrm{mL}$ to $1.0 \mathrm{mg} / \mathrm{mL})$ were supplemented with appropriate amounts of heparin $(0-1 \mathrm{mg} / \mathrm{mL})$ for the entire study. The low residual amounts of DMSO and high amount of heparin itself from the stock solution did not give rise to any fibrillation (Fig. S1F). ThT fluorescence was monitored on a Fluostar Omega (BMG Labtech, Germany) plate reader in bottom reading mode at $37^{\circ} \mathrm{C}$ under quiescent conditions. The plate was sealed with metal sealing tape to prevent evaporation. ThT fluorescence of all PSMs except PSM $\alpha 3$ was measured every 10 minutes with an excitation filter of $450 \mathrm{~nm}$ and an emission filter of $482 \mathrm{~nm}$ under quiescent conditions. For PSM $\alpha 3$, ThT fluorescence was measured every $20 \mathrm{~s}$ with an excitation filter of $450 \mathrm{~nm}$ and an emission filter of $482 \mathrm{~nm} .0-1 \mathrm{mg} / \mathrm{mL}$ heparin alone was tested in separate experiments. All measurements were in triplicate.

Synchrotron radiation circular dichroism spectroscopy (SRCD): SRCD spectra of PSM fibrils were collected at the AU-CD beamline of the ASTRID2 synchrotron, Aarhus University, Denmark. PSMs samples aggregated in the absence and presence of heparin were collected directly from the 96-well plates and pelleted at $13 \mathrm{krpm}$ for $30 \mathrm{~min}$. The supernatant was gently removed from each sample, and the pellet fraction was re-suspended in milliQ water. Three to five successive spectra of fibrillated PSMs (in the absence and presence of heparin) were recorded from 280 to $170 \mathrm{~nm}$ in a $0.2 \mathrm{~mm}$ path length cuvette with a dwell time of $2 \mathrm{sec}$ at $1 \mathrm{~nm}$ intervals at $25^{\circ} \mathrm{C}$. All SRCD spectra were processed and their respective averaged baseline (a solution containing all components of the sample, except the protein) subtracted, smoothing with a 7 pt Savitzky-Golay filter. The secondary structural content of individual SRCD spectra of PSM fibrils samples (in the absence and presence of heparin) was determined using DichroWeb [25, 26]. Each spectrum was fitted using three different analysis programs (Selecon3, Contin and CDSSTR) with the SP175 reference data set 
[27]. An average of the structural component contributions from the three analysis programs was used.

Thermal fibril stability by Circular dichroism analysis: Thermal CD spectra were recorded on a JASCO-810 (Jasco Spectroscopic Co., Ltd., Hachioji City, Japan) spectrophotometer equipped with a Peltier thermally controlled cuvette holder. At the end of ThT kinetics experiments, individual triplicate samples fibrillated in the absence and presence of the maximum concentrations of heparin i.e., $3 \mu \mathrm{g} / \mathrm{mL}$ for PSM $\alpha 1,40 \mu \mathrm{g} / \mathrm{mL}$ for PSM $\alpha 3,50 \mu \mathrm{g} / \mathrm{mL}$ for PSM $\alpha 4,250 \mu \mathrm{g} / \mathrm{mL}$ for PSM $\beta 1,1$ $\mathrm{mg} / \mathrm{mL}$ for PSM $\beta 2$ and $1 \mathrm{mg} / \mathrm{mL}$ for $\delta$-toxin were pelleted at $13 \mathrm{kpm}$ for $30 \mathrm{~min}$ and supernatant was removed. The remaining pellets were re-suspended in the same volume of milliQ water and thermal scans were recorded at $220 \mathrm{~nm}$ from 25 to $95^{\circ} \mathrm{C}$ with a step size of $0.1{ }^{\circ} \mathrm{C}$.

\section{Attenuated Total Reflectance Fourier Transform Infrared Spectroscopy (ATR-FTIR): PSM}

fibrils were prepared as above. $5 \mu \mathrm{L}$ of sample was applied on the surface of the ATR module and dried under a steam of nitrogen gas. FTIR spectra were recorded on a Tensor 27 FTIR instrument (Bruker optics, Billerica, Massachusetts, USA) equipped with an attenuated total reflection accessory with a continuous flow of $\mathrm{N}_{2}$ gas. Measurements were performed as an accumulation of 64 scans with a spectral resolution of $2 \mathrm{~cm}^{-1}$ over a range of 1000 to $3998 \mathrm{~cm}^{-1}$. Atmospheric compensation and baseline correlation was executed. The individual components of the spectrum were determined through second derivative analysis of curves by employing OPUS 5.5 software (Bruker, Billerica, Massachusetts, USA). For comparative studies, all absorbance spectra were normalized.

Transmission electron microscopy (TEM): The morphology of the PSMs species in the presence and absence of heparin was analyzed with TEM. $5 \mu \mathrm{L}$ of endpoint samples from the non-shaking ThT assay of each PSM was transferred to carbon-coated formvar electron microscopy grids 
followed by two minute incubation at room temperature. Buffer was then removed by blotting the grid with Whatman filter paper, washed with $5 \mu \mathrm{L}$ milliQ water and stained with $1 \%$ uranyl acetate for $2 \mathrm{~min}$, after which excess staining solution was removed with filter paper. Finally, the grids were washed twice with $5 \mu \mathrm{L}$ of milliQ and dried before analysis. Samples were viewed in a Morgagni 268 FEI Phillips Electron microscope equipped with a CCD digital camera, operated at $80 \mathrm{kV}$.

Heparin-PSM interactions measured using a peptide array: To probe interactions between heparin and PSMs, 351 different 10-residue peptides corresponding to different parts of the PSM sequences were immobilized on a microarray chip and incubated with fluorescein-labeled heparin [28]. In this array (full list provided in Table S3 and S4), each new peptide constituted a 10-residue window of a given PSM sequence shifted forward by 1 residue compared to the preceding peptide, giving a 9-residue overlap. For Ala scanning, each residue in a given 10-residue sequence was consecutively replaced by Ala before moving on to the next 10-residue peptide. As part of this procedure, the microarray was first blocked in a solution containing $3 \%(\mathrm{w} / \mathrm{v})$ whey protein in Tris saline buffer with $0.1 \%$ Tween-20 (TSB-T) incubated overnight at $4{ }^{\circ} \mathrm{C}$ and washed three times with TSB-T. Subsequently it was incubated with fluorescein-labeled heparin (diluted to 0.05 $\mathrm{mg} / \mathrm{mL}$ in PBS) for $4 \mathrm{~h}$ at room temperature. The microarray was washed 3 times with TSB-T, airdried in the dark and scanned using a Typhoon Trio scanner (GE Life Sciences, Pittsburgh, PA). Dot intensities in the scanned image were quantified using ImageJ.

Biofilm measurements with Crystal violet: Staphylococcus aureus (strain Newman) and three deletion mutants $\triangle \mathrm{PSM} \alpha, \triangle \mathrm{PSM} \beta$ and $\triangle \mathrm{PSM} \alpha / \beta$ were grown on an LB plate overnight. A single colony was transferred to TSB medium, grown up overnight at $37^{\circ} \mathrm{C}$ and then adjusted to OD $\sim 0.5$ and further diluted 1:100 in fresh PNG media (3.3 g/L peptone; $2.6 \mathrm{~g} / \mathrm{L} \mathrm{NaCl} ; 3.3 \mathrm{~g} / \mathrm{L}$ glucose). Heparin was added (from a $5 \mathrm{mg} / \mathrm{mL}$ stock in milliQ water) to the desired concentration and $100 \mu \mathrm{L}$ 
bioRxiv preprint doi: https://doi org/10.1101/2021.03.07.434294 t this version posted March 9,2021 . The copyright holder for this preprint (which was not certified by peer review) is the author/funder, who has granted bioRxiv a license to display the preprint in perpetuity. It is made available under aCC-BY-NC-ND 4.0 International license.

was then incubated in a 96 well plate for $24 \mathrm{~h}$ at $37^{\circ} \mathrm{C}$ with mild shaking $(50 \mathrm{rpm})$. The solutions were gently removed from all wells, after which the biofilm was washed once with PBS and air dried for $30 \mathrm{~min}$ at room temperature (RT). $100 \mu \mathrm{L}$ of crystal violet solution $2.3 \%$ (Sigma) was added to all wells, incubated at RT for 10 min and removed. All wells were washed twice with PBS. The plate was air dried for $30 \mathrm{~min}$, after which $150 \mu \mathrm{L}$ of $33 \%(\mathrm{v} / \mathrm{v})$ acetic acid was added to each well to release the dye attached to the biofilm. Finally, the absorbance of the released crystal violet was measured at $590 \mathrm{~nm}$. 


\section{Results}

\section{Aggregation kinetics of different PSMs is influenced by heparin}

To investigate the effect of heparin on the fibrillation of all seven PSM peptides (PSM $\alpha 1-4$, PSM $\beta 1-2$ and $\delta$-toxin), we incubated all PSMs individually (at fixed monomeric concentration) with different concentrations of heparin under quiescent conditions. Aggregation kinetics were monitored using the amyloid-binding dye ThT [29]. We have previously reported that PSM $\alpha 1$, PSM $\alpha 3$, PSM $\beta 1$ and PSM $\beta 2$ reproducibly aggregate to ThT-binding amyloid fibrils on the hour scale under quiescent conditions with different nucleating mechanism [11]. The addition of high molecular weight heparin dramatically changes the aggregation kinetics of all PSMs, but the effect varies between PSMs.

For PSM $\alpha 1$, as little as $1.0 \mu \mathrm{g} / \mathrm{mL}$ heparin increases end-level ThT fluorescence intensity and decreases the timescale for the completion of aggregation kinetics from $\sim 40 \mathrm{~h}$ to $\sim 25 \mathrm{~h}$ (Fig. 1A). Heparin also reduces the lag time from $22 \mathrm{~h}$ (heparin-free) to $7 \mathrm{hr}(3.0 \mu \mathrm{g} / \mathrm{mL}$ heparin) in a dosedependent manner (Fig. 1A). The lag phase decrease to $1-3 \mathrm{~h}$ up to $20 \mu \mathrm{g} / \mathrm{mL}$ heparin, above which it is completely abolished, accompanied by a reduction in ThT end point fluorescence (Fig. S1A).

PSM $\alpha 2$ was not observed to undergo fibrillation (measured as an increase in ThT fluorescence) in the absence or presence of up to $1 \mathrm{mg} / \mathrm{mL}$ of heparin (Fig. S1B). In contrast, PSM $\alpha 3$ fibrillated readily and with a sigmoidal time curve both in the absence and presence of $0-50 \mu \mathrm{g} / \mathrm{mL}$ heparin under quiescent conditions. Heparin significantly reduced lag times and correspondingly increased end-point ThT fluorescence. Thus $40 \mu \mathrm{g} / \mathrm{mL}$ heparin induced a 5-fold increase in fluorescence and a $\sim 4$ fold reduced lag time (Fig. 1B).

The last $\alpha$-PSM construct (PSM $\alpha 4$ ) shows the same ThT kinetics up to $20 \mu \mathrm{g} / \mathrm{mL}$ heparin though with an increase in overall ThT fluorescence (Fig. 1C). However when the ThT signals are normalized, the signals collapse to the same time curve (Fig. S1C). Above $25 \mu \mathrm{g} / \mathrm{mL}$ heparin, the 
lag time is abolished (Fig. S1D) and the data for 30-500 $\mu \mathrm{g} / \mathrm{ml}$ heparin could be fitted with an exponential decay. The resultant rate constant $(\mathrm{k})$ and amplitude of the reaction $(\mathrm{A})$ decreased with [heparin] (Fig. S1E).

For PSM $\beta 1$, a more complex scenario is revealed. In the absence of heparin, the peptide fibrillates with a lag time of $\sim 8 \mathrm{~h}$ (Fig. 1D). This increases to $\sim 18 \mathrm{~h}$ in $10-40 \mu \mathrm{g} / \mathrm{mL}$ heparin with a major decrease in ThT fluorescence intensity (Fig. 1D). There is then an abrupt shift around $50 \mu \mathrm{g} / \mathrm{mL}$ where the lag time remains $\sim 20 \mathrm{~h}$ but with a much shorter and steeper elongation phase, leading to a medium level of ThT fluorescence. Increasing [heparin] above $250 \mu \mathrm{g} / \mathrm{mL}$ only slightly increases lag-times. PSM $\beta 2$ fibrillates with a lag time of $\sim 1 \mathrm{~h}$ in the absence of heparin. Heparin increases both the lag time and the endpoint ThT fluorescence (Fig. 1E). While $\delta$-toxin on its own did not show any ThT fluorescence increase, heparin dramatically increased its ThT intensity with lag times decreasing from $\sim 45 \mathrm{~h}(0.2-0.4 \mathrm{mg} / \mathrm{mL}$ heparin) to $\sim 18-22 \mathrm{~h}(1 \mathrm{mg} / \mathrm{mL}$ heparin) (Fig. 1F).

To establish how heparin affects the microscopic steps during the aggregation of PSMs, we turned to the programme Amylofit [30]. Kinetic parameters from our previous analysis of PSM 1 aggregation in the absence of heparin [11] were used as fixed global parameters, while only one compound rate constant was individually fitted to each heparin concentration. This approach has previously been used for other amylogenic proteins to establish how e.g. inhibitors act on specific microscopic steps during aggregation [31-33]. We now go through the fits for the individual PSMs. Fits to kinetic data are shown in Fig. S2 and results from these fits in Fig. 2.

For PSM $\boldsymbol{\alpha 1}$, we found the best fit when we allowed $\mathrm{k}_{+} \mathrm{k}_{2}$ to vary and restricted $\mathrm{k}_{+} \mathrm{k}_{\mathrm{n}}, n_{\mathrm{c}}$ and $n_{2}$ to the heparin-free values (Fig. S2A). Since $k_{+} k_{n}$ was kept constant during the data fitting, the kinetic parameter within the parameter $\mathrm{k}_{+} \mathrm{k}_{2}$ mostly affected by the presence of heparin is expected to be $\mathrm{k}_{2}$. Interestingly, $\log \mathrm{k}+\mathrm{k} 2$ values increase in a linear fashion when plotted against [heparin] (Fig. 2A). Similar linear relationships are seen in plots of the log of unfolding rate constants versus denaturant 
(urea, $\mathrm{GdmCl}$ ) [34] or surfactant (SDS) concentrations [35]. While denaturants are present at molar concentrations (> $100 \mathrm{mg} / \mathrm{mL}$ ) and rely on weak interactions with the protein, SDS effects are seen at low $\mathrm{mM}(\sim 1 \mathrm{mg} / \mathrm{mL})$ concentrations and are ascribed to high affinities (driven by electrostatics) and clustering on the protein (driven by hydrophobic effects). Given the low concentrations of heparin used $(\sim 1 \mu \mathrm{g} / \mathrm{mL})$, these interactions are clearly strong and may also be cooperative in nature.

Following this pattern, the best Amylofit fits of PSMa3 aggregation in heparin were also obtained by varying $\mathrm{k}_{+} \mathrm{k}_{2}$, indicating that $\mathrm{k}_{2}$ is most affected as is the case for PSM $\alpha 1$ (Fig. S2B, Table 1). This leads to a similar semi-log relationship (Fig. 2B), although the slope is reduced by a factor $\sim 30$ (slope of semi-log plots: $\sim 0.54$ for PSM $\alpha 1$ and 0.02 for PSM $\alpha 3$ ), indicating a somewhat weaker heparin-PSM $\alpha 3$ interaction.

PSMß1-heparin interactions follow two different modes below and above $50 \mu \mathrm{g} / \mathrm{mL}$ heparin and are accordingly fitted as two separate sets of data in Amylofit. Data with 0-40 $\mu \mathrm{g} / \mathrm{mL}$ heparin are best fitted when $\mathrm{k}_{+} \mathrm{k}_{\mathrm{n}}$ values are allowed to vary while keeping the other kinetic parameters $\mathrm{n}_{\mathrm{c}}, \mathrm{n}_{2}$ and $\mathrm{k}_{2} \mathrm{k}_{+}$constant (Fig. S2C). The latter indicates that $\mathrm{k}_{+}$can be considered constant so that heparin mainly affects $\mathrm{k}_{\mathrm{n}}$, i.e. primary nucleation. The value for $\mathrm{k}_{\mathrm{n}} \mathrm{k}_{+}$remains constant up to ca. $10 \mu \mathrm{g} / \mathrm{mL}$ heparin, after which it increases in a semi-log linear manner (Fig. 2C). Data with 50-250 $\mu \mathrm{g} / \mathrm{mL}$ heparin can be fitted by allowing $\mathrm{k}_{\mathrm{n}} \mathrm{k}_{+}$to vary with [heparin] while maintaining a single (global) fit value for $\mathrm{k}_{+} \mathrm{k}_{2}$ (Fig. S2D). The values of $\mathrm{knk}_{+}$decrease dramatically with [heparin], which we again attribute to a reduction in $k_{\mathrm{n}}$ since $k_{+}$is constant. This time, linearity is only seen when data are plotted in a log-log plot (Fig. 2D). Such log-log linearity is also seen for e.g. ligand-binding or protonation/deprotonation systems, i.e. strong and specific interactions. 
In the absence of heparin, PSM $\boldsymbol{2} 2$ follows a primary nucleation and elongation dominated mechanism [11]. However, in the presence of heparin, the best fit is obtained using a secondary nucleation dominated aggregation model where $\mathrm{k}_{+} \mathrm{k}_{\mathrm{n}}$ is kept a global constant and $\mathrm{k}_{+} \mathrm{k}_{2}$ is allowed to vary. As with PSM $\beta 2$, linearity is only seen when data are plotted in a log-log plot (Fig. 2E). Heparin hence induces secondary nucleation in PSM $\beta 2$ while decreasing the aggregation kinetics by inhibiting the peptide's primary nucleation process (Fig. S2E and Table 1). This is also reflected in the value of $\mathrm{k}_{\mathrm{n}} \mathrm{k}+$ which is 3 orders of magnitude lower in the presence of heparin $\left(0.0483 \mathrm{M}^{-\mathrm{nc}} \mathrm{h}^{-}\right.$ $\left.{ }^{2}\right)$ than its absence $\left(48.8 \mathrm{M}^{-\mathrm{nc}} \mathrm{h}^{-2}\right)$.

While $\delta$-toxin on its own did not show any ThT fluorescence increase, heparin dramatically increased its ThT intensity. Since we did not have parameters for heparin-free aggregation, we fitted the data satisfactorily using a secondary nucleation dominated aggregation mechanism with $\mathrm{knk}_{+}$as global fit and $\mathrm{k}+\mathrm{k}_{2}$ as individual fits for each heparin concentration (Fig. S2F). k+k2 increases with increasing heparin but in a poorly linear manner (Fig. 2F).

It should be noted that fits with better MRE values can be obtained for the kinetic data for PSM peptides in the presence of heparin if the kinetic paramters are set to global fit instead of held as global constants (Fig. S3 and Table S1). This is to be expected since this allows more degrees of freedom during the data fitting. However we find it most consistent to maintain parameters obtained from our previous experiments.

\section{Heparin has modest effects on the secondary structure and thermal stability of PSM fibrils}

Next we addressed whether heparin affected the secondary structures of the fibrillar aggregates. For this we turned to Synchrotron Radiation Circular Dichroism (SRCD) and attenuated total internal reflection Fourier transform infrared (ATR-FTIR) spectroscopy. Each CD and FTIR spectrum was deconvoluted using the DichroWeb server $[25,26]$ and the OPUS 5.5 software, respectively. 
Individual CD spectra are shown in Fig. 3A and Fig. S4ABDE with deconvolutions in Fig. 3B and Fig. S4CF; FTIR spectra are presented in Fig. 3C and Fig. S5 with deconvolution results in Fig. 3D.

In the absence of heparin, most fibrillar aggregates displayed a single minimum typical of $\beta$-sheets as seen for PSM $\alpha 1$ (218nm), PSM $\alpha 4(218 \mathrm{~nm}), \operatorname{PSM} \beta 1$ and PSM $\beta 2(220 \mathrm{~nm})$. These peak positions are in good agreement with previous findings [36]. The FTIR spectra of fibrils related to these four peptides were found to be very similar, with a well-defined intense peak at $\sim 1625 \mathrm{~cm}^{-1}$ indicative of amyloid $\beta$-sheet and a minor shoulder at $\sim 1655 \mathrm{~cm}^{-1}$ indicative of $\alpha$-helical conformation (Fig. 3A and 3C).

Addition of heparin had a variety of effects on fibril structure. PSM $\alpha 1$ showed a slightly shifted minimum ellipticity of 3 and $6 \mathrm{~nm}$ in the presence of $1 \mu \mathrm{g} / \mathrm{mL}$ and $3 \mu \mathrm{g} / \mathrm{mL}$ heparin respectively (Fig. S4A). PSM $\alpha 3$ aggregates in presence and absence of heparin show cross- $\alpha$-helical structure in both SRCD and FTIR spectra, in good agreement with previous reports $[37,38]$. The SRCD and FTIR spectra for PSM $\alpha 4$ in absence and presence of heparin were internally consistent (Fig. 3AC and Fig. S4B). An FTIR peak around $\sim 1690 \mathrm{~cm}^{-1}$ suggests anti-parallel beta-sheets. SRCD spectra of PSM $\beta 1$ and PSM $\beta 2$ heparin-free aggregates are similar to those in the presence of heparin (Fig. 3A and Fig. 3B, S4D). Further, SRCD and FTIR spectra clearly indicate that heparin favors amyloid formation in $\delta$-toxin and significant secondary structural changes were observed in the presence of various concentrations of heparin (Fig. 3A and Fig. S4EF).

The thermal stability of the PSM aggregates in absence and presence of heparin was evaluated by CD spectroscopy. Fig. S6 shows thermal scans monitored by ellipticity at $220 \mathrm{~nm}$ for fibrils (PSM $\alpha 1, \mathrm{PSM} \alpha 3$ and PSM $\alpha 4$ ) from $25^{\circ} \mathrm{C}$ to $95^{\circ} \mathrm{C}$. Neither PSM $\alpha 1$ and PSM $\alpha 4$ nor $\beta$ PSMs fibrils undergo any significant loss in signal up to $95^{\circ} \mathrm{C}$, indicating thermally stable $\beta$-sheet structure (Fig. S6A, B). However, PSMa3 fibrils are thermally unstable both conditions in the absence and 
presence of heparin, as a loss of structure is seen above $50^{\circ} \mathrm{C}$ (Fig. S6A). Hence heparin does not change the thermal stability of the fibrils.

\section{Heparin shows variable effects on the fibril morphology of PSMs}

The morphologies of the peptide fibrils in the absence and presence of heparin were analyzed by transmission electron microscopy (TEM). TEM analysis of PSM $\alpha 1$ incubated in the absence and presence of heparin showed amyloid-like fibrils in both cases (Fig. 4A and 4B) though fibrils prepared with heparin were slightly thicker. No aggregated species were observed for PSM $\alpha 2$ (Fig. S7A-B) in both conditions, consistent with the lack of increase in ThT fluorescence upon incubation with and without heparin. In the absence of heparin, PSM $\alpha 3$ formed long rod like fibrils (Fig. 4C) which in the presence of heparin shows very similar fibrillar structure (Fig. 4D).

Heparin also encouraged formation of PSM $\alpha 4$ fibrils (Fig. 4E, F). On their own, PSM $\alpha 4$ displays very thin fibrils visible at higher magnification with some distribution of spherical aggregates organized into small clusters on the grid which upon incubation with heparin show nicely separated fibrillar structure (Fig. 4E). PSM $\beta 1$ on its own formed highly ordered arrays of laterally associated fibers (Fig. 4G) which with heparin changed to disentangled thin aggregates (Fig. 4H and Fig. S7C). We do not observe significant morphological difference between PSM $\beta 2$ fibrils obtained in the absence and presence of heparin (Fig. 4I and 4J). Finally, TEM of $\delta$-toxin confirmed the aggregation potential of heparin. While there were no visible fibrils in $\delta$-toxin on its own, heparin led to large networks of thin fibers (Fig. 4K and 4L, Fig. S7D).

\section{Interactions between heparin and PSM residues analyzed by peptide arrays}

We explored the interaction between fluorescein-labeled heparin and PSM sequences using a peptide array chip displaying 10-residue immobilized peptides in staggered arrangements (Tables S3 and S4). Thanks to the fluorescein label, it was possible to quantitate the amount of heparin 
bound to each peptide fragment (Fig. 5). All $\alpha$-type PSMs bind more heparin than $\beta$ PSM, but the intensity is not equally distributed along the length of each PSM. High heparin affinity is shown by peptides corresponding to the $\mathrm{N}$-terminal half of $\alpha$-PSMs and the middle and C-terminal part of $\beta$ PSMs. We attempted to probe possible correlations between signal intensity and the peptides' physical-chemical characteristics such as charge and hydrophobicity [39]. As shown in Table 2, the sequence charge is the most significant contributor, especially for $\beta$ PSMs, with higher positive charge leading to higher signal intensities. This is to be expected in view of heparin's highly anionic nature.

Note however that a priori we cannot predict whether high binding by heparin would promote aggregation (e.g. by forming a template for the extended state, leading to amyloid) or inhibit it (by sequestering monomers from interacting with other monomers). According to our ThT-assays (Fig. 1) heparin accelerates the fibrillation of PSM $\alpha 1, \operatorname{PSM} \alpha 3, \operatorname{PSM} \alpha 4, \delta$-toxin and PSM $\beta 1$ at low heparin concentrations, whereas it inhibited PSM $\beta 1$ at high heparin concentrations as well as PSM $\beta 2$. We conclude from this that the high affinity of heparin to $\alpha$-PSMs' N-termini promotes fibrillation, whereas binding to the middle and C-terminal regions of $\beta$ PSMs inhibits fibrillation.

To elucidate the role of individual residues in the heparin interaction, we carried out an Ala scan of all PSMs (Fig. 6).

In PSM $\alpha 1$, an increase in signal intensity compared to wildtype was caused by mutations M1A, G2A and I4A (which maintain the same charge but lead to either a fall or a rise in hydrophobicity) (Table S1). A decrease in signal was caused by removal of positive charge (K9A, K12A, and K21A). This illustrates clearly how electrostatic interactions are the main (but not the only) drivers of heparin-peptide interactions (Fig. 6A). 
Similarly, K-to-A mutations in PSM $\alpha 2$ and also in the rest of PSM peptides (including PSM $\alpha 3$, PSM $\alpha 4$, $\delta$-toxin, PSM $\beta 1$ and PSM $\beta 2$ ) decreased heparin binding, but so did loss of hydrophobicity: mutations I3A, I6A and F18A for PSM $\alpha 2$ and I3A, I11A and L14A for PSM $\alpha 1$ led to a 25-50\% drop in intensity. We were unable to obtain ThT fibrillation curves for PSM 2 , thus we cannot conclude what effect binding would have on its fibrillation kinetics.

Moreover, removal of negative charge (e.g. for E and D to A residues) leads to an increase in signal intensity, but mutations altering hydrophobicity had an even more marked increase in binding for peptides with same charges (Table S2). Mutation M1A also led to increase in signal for PSM $\alpha 3$ and PSM $\alpha 4$ same as PSM $\alpha 1$. For PSM $\alpha 3$, K-to-A mutations led to the highest decrease in signal intensity, again emphasizing the role of charge. For PSM $\alpha 4$ except the mutations affect the charge, the truncation mutations T6A, I12A, I14A, I15A and I17A increased binding as did the insertion mutation G5A. G-to-A/T mutations increase hydrophobicity while I-to-A decrease it; neither affect charge. Interestingly, the I-to-A mutation led to a drop in signal for PSM $\alpha 1$ (I4A, I11A) and PSM $\alpha 2$ (I3A, I4A, I6A and I11A) but increased it for PSM $\alpha 4$ and $\delta$-toxin (I16A and I17A), indicating different roles for Ile.

For $\delta$-toxin, the Ala scan of first 10 residues did not show major changes. For the second 10 residues, almost all mutations led to higher signal intensity and the most important mutations are D11A, W15A, I16A, I17A and D18A. Ala scans of the last 6 residues increased the signal intensities to the highest level. Remarkably, this was also the case for 3 K-to-A mutations. Note that these 6 spots are the only positively charged spots in Ala scan of $\delta$-toxin (which does not fibrillate in the absence of heparin), and they could be binding partners for heparin that promote fibril formation. Also in PSM $\beta 1$ and PSM $\beta 2$, removal of anionic Glu/Asp led to increased binding, while removal of Lys decreased signal intensity (Fig. 6 F and G). 
Table 3 shows that for PSM $\beta 1$ and PSM $\beta 2$, charge is most strongly correlated with binding ( $p$ values $6.12 * 10^{-6}$ and $3.01 * 10^{-9}$ respectively), while hydrophobicity has a much weaker effect on PSM $\beta 1$ ( $p$-value 0.025) and PSM $\beta 2$ ( $p$-value 0.313). Based on multiple regression analysis with two variants charge and hydrophobicity, the predicted signal intensities nicely fit the measured signals, indicating the central importance of these two parameters in the interaction between PSMs and heparin (Fig. S8).

\section{Heparin promotes biofilm formation both in the presence and absence of PSM $\alpha / \beta$}

To put our observations in a biological context, we investigated how heparin affects biofilm formation. Accordingly, we incubated S.aureus Newman strain as a model of S.aureus human infections having a robust virulence phenotype and ability to form biofilm [40, 41] and three different PSM mutants of this strain with 10-200 $\mu \mathrm{M}$ of heparin. Incubation of wild type S. aureus with heparin increased the amount of biofilm significantly at $>10 \mu \mathrm{g} / \mathrm{mL}$ heparin (Fig. 7). A strain that only produces $\operatorname{PSM} \alpha(\triangle \mathrm{PSM} \beta)$ show a higher biofilm formation even at low [heparin] compared to $\triangle \mathrm{PSM} \alpha$; this could be caused by the ability of heparin to induce PSM $\alpha$ fibrillation. However, an increase in the biofilm formation of $\Delta \mathrm{PSM} \alpha / \beta$ in the presence of heparin indicates that other mechanisms are also involved in biofilm formation. 


\section{Discussion}

Staphylococcus aureus is an important human pathogen causing many different hospital- and community-associated infections. This is promoted by its ability to form biofilm, aided by amyloidforming PSMs [42], and thus increase resistance to antibiotics [43]. S.aureus is particularly prone to form biofilm on catheters; furthermore heparin is commonly used as anticoagulant in these catheters [17]. This inspired us to investigate the effect of heparin on PSMs fibrillation.

\section{Heparin shows a range of effects on aggregation which are very sensitive to peptide sequence}

Our study highlighted that heparin accelerates fibril formation for $\alpha$ PSMs (PSM $\alpha 1$, PSM $\alpha 3$, PSM $\alpha 4$ and $\delta$-toxin) at concentrations as low as $1 \mu \mathrm{g} / \mathrm{mL}(\mathrm{PSM} \alpha 1)$, though the effect was generally seen in the range $0.02-1 \mathrm{mg} / \mathrm{mL}$. In contrast, heparin inhibits the fibrillation of the two PSM $\beta \mathrm{s}$. The interaction is mainly driven by electrostatic interactions between PSMs and heparin as seen for many other protein-heparin interactions [44].

In the PSM $\alpha$ family, heparin induces fibrillation by reducing nucleation time and enhancing the ThT end-level. It also induces aggregation of the otherwise non-aggregating $\delta$-toxin. PSM $\beta 1$ is inhibited in two different modes: below $50 \mu \mathrm{g} / \mathrm{mL}$ heparin, heparin inhibits the nucleation step but does not affect growth rates, but above $50 \mu \mathrm{g} / \mathrm{mL}$ heparin increased growth rate and ThT end-levels while increasing the lag phase. Heparin had mixed effects on PSM $\beta 2$, increasing the lag-time as well as ThT-end levels. It is remarkable that PSM $\beta 1$ and PSM $\beta 2$ show very distinct aggregation behavior despite their high similarity. PSM $\beta 1$ aggregates efficiently at very low concentrations and responds in a bimodal manner to heparin, with different behavior ats at low versus high heparin concentrations. Amylofit analysis reveals that the $\mathrm{k}_{+} \mathrm{k}_{2}$ is mostly affected in the $\alpha$-PSM peptide whereas incubation with heparin leads to variations in $\mathrm{k}_{+} \mathrm{k}_{\mathrm{n}}$ for $\beta$-PSM peptides, thus highlighting the effect of heparin on the nucleation phase of aggregation for the $\beta$-PSM peptides in particular. 
The marked increase in the final ThT-level is also seen as a higher level of fibril formation. Similar effects have been reported for amyloidogenic proteins like $\alpha$-synuclein and transthyretin [21, 23]. Heparin co-pellets with the aggregates, showing strong binding and a possible templating role in fibrillation $[21,23,45,46]$. The shortening of the lag phase seen for PSM $\alpha 1$ and PSSM $\alpha 3$ might be caused by heparin's induction of a conformational changes favoring fibrillation process or by stabilizing early-stage aggregates [14, 23, 47].

\section{Cationic heparin-binding motifs in the aPSMs family may drive fibrillation}

Heparin-binding domains often contain a high proportion of positively charged Lys and Arg which can interact with anionic GAGs [14]. These residues often occur as motifs with basic amino acids in close proximity like $\mathrm{XBBBXXBX}$ and $\mathrm{XBBXBX}$ sequences where $\mathrm{B}$ and $\mathrm{X}$ are basic and nonbasic residues respectively [48, 49]. The proximity of $\mathrm{B}$ residues likely leads to cooperative binding effects. Such motifs are found in the $\alpha \mathrm{PSMs}$ family, e.g. "KVIK" in PSM $\alpha 1$, "KLFK" in PSM $\alpha 3$, "KIIK" in PSM $\alpha 4$ and "KFTKK" in $\delta$-toxin. For $\beta$ PSMs the Lys residues are further from each other and their net charge at $\mathrm{pH} 7$ is overall negative. This might explain the difference in behavior. Our peptide array data also confirm the importance of positively charged residues (mainly Lys) whose replacement by Ala abolished heparin binding. Further, removal of negatively charged residues ( $\mathrm{D}$ and $\mathrm{E}$ residues) increased the binding of heparin. Both confirm the importance of electrostatic interaction between PSMs and heparin. Alanine scan of peptides on peptide array indicated that charge is more important than hydrophobicity as K-to-A mutations increased the hydrophobicity but did not increase the binding of heparin (table S2). The structure of PSM $\alpha 3$ fibrils reveals that some Lys residues are not involved in intermolecular fibrillar contacts but are speculated to be related to the cytotoxicity of the peptide towards human cells (e.g. through interactions with the membrane) as mutations of these residures to Ala results in reduced toxicity 
[50]. This implies that these residues can take part in electrostatic interactions with heparin without interfering with amyloid formation.

Structural analysis of fibrils demonstrate typical $\beta$-sheet fibrils for PSM $\alpha 1$ (218nm), PSM $\alpha 4$ (218 $\mathrm{nm}), \operatorname{PSM} \beta 1$ and PSM $\beta 2(220 \mathrm{~nm})$ as reported $[11,36,51]$ and this is largely unaffected by heparin. Simiarly, the characteristic but unusual cross- $\alpha$ fibrils of PSM $\alpha 3$ are maintained in the presence of heparin $[9,50]$. Heparin led the non-aggregating $\delta$-toxin peptide (which forms $\alpha$-helices in solution) to form $\beta$-sheet amyloid fibrils. All fibrils show high thermal stability except the cross- $\alpha$ PSM $\alpha 3$ fibrils which are unstable above $50^{\circ} \mathrm{C}$. Similar modest thermal stability has been reported for fibrils of PSM $\alpha 3$-LFKFFK segment [51]. Thus the cross- $\alpha$ structure may be inherently less stable than cross- $\beta$ fibrils due to the difference in the type of intermolecular contacts.

Incubation of $S$. aureus Newman strain and its psm mutants in presence of heparin show biofilm formation significantly promoted in wild type and $\triangle \mathrm{PSM} \beta$, but not so pronounced in the case of $\triangle \mathrm{PSM} \alpha$. Gratifyingly, this is consistent with the inducing and inhibiting effect of heparin on fibrillation of $\alpha$ PSMs and $\beta$ PSMs respectively. The role of complemenmtary electrostatics is also confirmed by the observation that positively charged polysaccharides like chitosan do not increase biofilm formation $[17,52,53]$.

In summary, our study uncovered a diversity of mechanistic effects of heparin on the fibrillation of PSMs. There were modest differences in the kinetics of the heparin-stimulated fibrillation reaction of PSMs, with the kinetics being fastest with PSM $\alpha 3$ and slowest with $\delta$-toxin and there are significant differences in the seven PSM peptides' affinities for heparin. While heparin promotes fibrillation of $\alpha$ PSMs and $\delta$-toxin, it inhibited but did not abolish $\beta$ PSM fibrillation (Fig. 9), consistent with its ability to promote $S$. aureus biofilm formation. Heparin mostly targets the nucleation step and thus the lag phase, while increasing ThT end levels suggest higher levels of 
fibrillation. Furthermore, our data demonstrate that positively charged residues close to each other in $\alpha \mathrm{PSMs}$ and $\delta$-toxin provide suitable region to stabilize binding of the highly negative charge heparin. Additionally, in contrast to most previous studies showing only the effects of heparin as a promoter of fibrillation $[54,55]$, our results demonstrated that heparin has a dual effect and it acts as an inducer or inhibitor in the fibrillation of PSMs, which main contribute both to the integrity and dynamics of formation of biofilms.

Acknowledgments: D.E.O. gratefully acknowledges support by the Independent Research Foundation Denmark | Technical Sciences (grant no. 6111-00241B) and the Independent Research Foundation Denmark | Natural Sciences (grant no. 8021-00208B). M.A. gratefully acknowledges support by Aarhus University Research Foundation. Furthermore, we acknowledge the award of beam time on the AU-CD beam line at ASTRID2, under project number ISA-20-1013 and Dr. Nykola Jones for assistance for data collection.

Conflict of interest: The authors declare no conflict of interest.

Author contribution: Z.N., M.Z., M.A. and D.E.O. designed experiments, M.Z. and Z.N. carried out the experiments, M.Z., Z.N., M.A. and D.E.O. analyzed the data, Z.N., M.Z., M.A. and D.E.O. wrote, reviewed and edited the manuscript while D.E.O. and M.A. acquired funding. 
bioRxiv preprint doi: https://doi.org/10.1101/2021.03.07.434294; this version posted March $9,2021$. The copyright holder for this preprint (which was not certified by peer review) is the author/funder, who has granted bioRxiv a license to display the preprint in perpetuity. It is made available under aCC-BY-NC-ND 4.0 International license.

\section{Tables:}

Table 1. Kinetic parameters of data fitting using the webserver Amylofit in the presence of heparin using global constants for all parameters (last row) except one which is fitted to individual heparin concentrations

\begin{tabular}{|c|c|c|c|c|c|c|c|c|c|}
\hline $\begin{array}{l}\text { Heparin } \\
(\mu \mathrm{g} / \mathrm{mL})\end{array}$ & PSMa1 & $\begin{array}{l}\text { Heparin } \\
(\mu \mathrm{g} / \mathrm{mL})\end{array}$ & PSMa3 & $\begin{array}{l}\text { Heparin } \\
(\mu \mathrm{g} / \mathrm{mL})\end{array}$ & PSMß1 & $\begin{array}{l}\text { Heparin } \\
(\mu \mathrm{g} / \mathrm{mL})\end{array}$ & PSMß1 & $\begin{array}{l}\text { Heparin } \\
(\mu \mathrm{g} / \mathrm{mL})\end{array}$ & PSMß2 \\
\hline & $\mathbf{k}_{+} \mathbf{k}_{2}$ & & $\mathbf{k}_{+} \mathbf{k}_{2}$ & & $\mathbf{k}_{+} \mathbf{k}_{\mathbf{n}}$ & & $\mathbf{k}_{+} \mathbf{k}_{\mathbf{n}}$ & & $\mathbf{k}_{+} \mathbf{k}_{2}$ \\
\hline 0 & 167 & 0 & $4.06 \times 10^{+5}$ & 0 & $1.49 \times 10^{+17}$ & 50 & $1.52 \times 10^{+12}$ & 0.1 & $2.49 \times 10^{+10}$ \\
\hline 0.5 & 257 & 10 & $6.73 \times 10^{+5}$ & 5 & $1.19 \times 10^{+17}$ & 75 & $3.66 \times 10^{+10}$ & 0.15 & $1.86 \times 10^{+10}$ \\
\hline 1 & 396 & 20 & $8.24 \times 10^{+5}$ & 10 & $1.13 \times 10^{+17}$ & 100 & $5.04 \times 10^{+7}$ & 0.2 & $1.78 \times 10^{+10}$ \\
\hline 1.5 & 831 & 25 & $1.07 \times 10^{+6}$ & 20 & $1.90 \times 10^{+17}$ & 150 & $4.09 \times 10^{+3}$ & 0.25 & $1.50 \times 10^{+10}$ \\
\hline 2 & $2.47 \times 10^{+3}$ & 30 & $1.75 \times 10^{+6}$ & 30 & $4.51 \times 10^{+17}$ & 200 & $1.57 \times 10^{+5}$ & 0.5 & $7.23 \times 10^{+9}$ \\
\hline 3 & $5.78 \times 10^{+3}$ & 40 & $2.66 \times 10^{+6}$ & 40 & $6.96 \times 10^{+17}$ & 250 & $1.32 \times 10^{+4}$ & 1 & $6.27 \times 10^{+9}$ \\
\hline \multicolumn{2}{|c|}{$\begin{array}{l}\mathrm{m}_{0}=110 \mu \mathrm{M} \\
\mathrm{n}_{\mathrm{c}}=7.84 \times 10^{-6} \\
\mathrm{k}_{+} \mathrm{k}_{\mathrm{n}}=6.98 \times 10^{-5} \\
\left(\mathrm{conc}^{-\mathrm{n} 2-1} \mathrm{time}^{-2}\right) \\
\mathrm{n}_{2}=0.00166 \\
\text { MRE:0.00754 }\end{array}$} & \multicolumn{2}{|c|}{$\begin{array}{l}\mathrm{m}_{0}=96 \mu \mathrm{M} \\
\mathrm{n}_{\mathrm{c}}=0.600 \\
\mathrm{k}_{+} \mathrm{k}_{\mathrm{n}}=257 \\
\left(\mathrm{conc}^{-\mathrm{n} 2-1} \text { time }^{-2}\right) \\
\mathrm{n}_{2}=0.123 \\
\text { MRE:0.00570 }\end{array}$} & \multicolumn{2}{|c|}{$\begin{array}{l}\mathrm{m}_{0}=55 \mu \mathrm{M} \\
\mathrm{n}_{\mathrm{c}}=3.92 \\
\mathrm{k}_{+} \mathrm{k}_{2}=4.23 \times 10^{+3} \\
\left(\mathrm{conc}^{-\mathrm{n} 2-1} \text { time }^{-2}\right) \\
\mathrm{n}_{2}=0.200 \\
\mathrm{MRE}: 0.00423\end{array}$} & \multicolumn{2}{|c|}{$\begin{array}{l}\mathrm{m}_{0}=55 \mu \mathrm{M} \\
\mathrm{n}_{\mathrm{c}}=3.92 \\
\mathrm{n}_{2}=0.2 \\
\text { Global fit: } \\
\mathrm{k}_{+} \mathrm{k}_{2}=6.71 \times 10^{+5} \\
\left(\text { conc }^{-\mathrm{n} 2-1} \text { time }^{-2}\right) \\
\text { MRE: } 0.00905\end{array}$} & \multicolumn{2}{|c|}{$\begin{array}{l}\mathrm{m}_{0}=5.61 \mu \mathrm{M} \\
\mathrm{n}_{\mathrm{c}}=0.572 \\
\mathrm{n}_{2}=1.00 \\
\mathrm{k}_{+} \mathrm{k}_{2}=3.05 \times 10^{+4} \\
\left(\text { conc }^{-\mathrm{n} 2-1} \text { time }^{-2}\right) \\
\text { Global fit: } \\
\mathrm{k}_{+} \mathrm{k}_{\mathrm{n}}=0.0483 \\
\left(\text { conc }^{-\mathrm{n} 2-1} \text { time }^{-2}\right) \\
\text { MRE: } 0.0117\end{array}$} \\
\hline
\end{tabular}

Table 2. $p$-values from multiple regression analysis of the correlation between signal intensity and the two variants charge and hydrophobicity.

\begin{tabular}{|c|c|c|}
\hline Peptide & Charge & Hydrophobicity \\
\hline PSM $\alpha 1$ & 粪萧 & 萧 \\
\hline $\mathrm{PSM} \alpha 2$ & 䊑 & 萧 \\
\hline PSM $\alpha 3$ & 潾 & - \\
\hline $\mathrm{PSM} \alpha 4$ & 䊑 & - \\
\hline PSM $\beta 1$ & 萧潾粪 & 萧 \\
\hline PSM $\beta 2$ & 粪溓粪 & 萧 \\
\hline
\end{tabular}

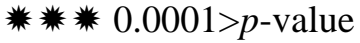

䊑 $0.0001>p$-value $>0.001$

橉 $0.001>p$-value $>0.05$

- $p$-value $>0.05$
Table 3. $p$-values from multiple regression analysis of the correlation between signal intensity and the two variants charge and hydrophobicity

\begin{tabular}{|c|c|c|}
\hline Peptide & Charge & Hydrophobicity \\
\hline PSM $\alpha 1$ & 萧洋 & \\
\hline PSM $\alpha 2$ & 萧粪 & 举橉 \\
\hline PSM $\alpha 3$ & 样 潾 & - \\
\hline PSM $\alpha 4$ & 萧萧洋 & - \\
\hline PSM $\beta 1$ & 萧萧垱 & 档 \\
\hline PSM $\beta 2$ & 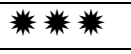 & - \\
\hline
\end{tabular}

粪潾 $0.0001>p$-value

萧 $0.0001>p$-value $>0.001$

萧 $0.001>p$-value $>0.05$

- $p$-value $>0.05$ 
bioRxiv preprint doi: https://doi.org/10.1101/2021.03.07.434294; this version posted March 9, 2021. The copyright holder for this preprint (which was not certified by peer review) is the author/funder, who has granted bioRxiv a license to display the preprint in perpetuity. It is made available under aCC-BY-NC-ND 4.0 International license.

\section{References}

[1] D. Otzen, R. Riek, Functional amyloids, Cold Spring Harbor Perspectives in Biology 11(12) (2019) a033860.

[2] M.R. Chapman, L.S. Robinson, J.S. Pinkner, R. Roth, J. Heuser, M. Hammar, S. Normark, S.J. Hultgren, Role of Escherichia coli curli operons in directing amyloid fiber formation, Science 295(5556) (2002) 851855.

[3] M.S. Dueholm, S.V. Petersen, M. Sønderkær, P. Larsen, G. Christiansen, K.L. Hein, J.J. Enghild, J.L. Nielsen, K.L. Nielsen, P.H. Nielsen, Functional amyloid in Pseudomonas, Molecular microbiology 77(4) (2010) 1009-1020.

[4] D. Romero, C. Aguilar, R. Losick, R. Kolter, Amyloid fibers provide structural integrity to Bacillus subtilis biofilms, Proceedings of the National Academy of Sciences 107(5) (2010) 2230-2234.

[5] K. Schwartz, A.K. Syed, R.E. Stephenson, A.H. Rickard, B.R. Boles, Functional amyloids composed of phenol soluble modulins stabilize Staphylococcus aureus biofilms, PLoS Pathog 8(6) (2012) e1002744.

[6] R. Wang, K.R. Braughton, D. Kretschmer, T.-H.L. Bach, S.Y. Queck, M. Li, A.D. Kennedy, D.W. Dorward, S.J. Klebanoff, A. Peschel, Identification of novel cytolytic peptides as key virulence determinants for community-associated MRSA, Nature medicine 13(12) (2007) 1510-1514.

[7] B. Surewaard, C. De Haas, F. Vervoort, K. Rigby, F. DeLeo, M. Otto, J. Van Strijp, R. Nijland, Staphylococcal alpha-phenol soluble modulins contribute to neutrophil lysis after phagocytosis, Cellular microbiology 15(8) (2013) 1427-1437.

[8] C. Mehlin, C.M. Headley, S.J. Klebanoff, An inflammatory polypeptide complex from Staphylococcus epidermidis: isolation and characterization, The Journal of experimental medicine 189(6) (1999) 907-918. [9] E. Tayeb-Fligelman, O. Tabachnikov, A. Moshe, O. Goldshmidt-Tran, M.R. Sawaya, N. Coquelle, J.-P. Colletier, M. Landau, The cytotoxic Staphylococcus aureus PSM $\alpha 3$ reveals a cross- $\alpha$ amyloid-like fibril, Science 355(6327) (2017) 831-833.

[10] G.Y. Cheung, K. Rigby, R. Wang, S.Y. Queck, K.R. Braughton, A.R. Whitney, M. Teintze, F.R. DeLeo, M. Otto, Staphylococcus epidermidis strategies to avoid killing by human neutrophils, PLoS Pathog 6(10) (2010) e1001133.

[11] M. Zaman, M. Andreasen, Cross-talk between individual phenol soluble modulins in S. aureus biofilm enables rapid and efficient amyloid formation, Elife 9 (2020) e59776.

[12] K. Schwartz, M. Ganesan, D.E. Payne, M.J. Solomon, B.R. Boles, Extracellular DNA facilitates the formation of functional amyloids in S taphylococcus aureus biofilms, Molecular microbiology 99(1) (2016) 123-134.

[13] Z. Najarzadeh, J.N. Pedersen, G. Christiansen, S.A. Shojaosadati, J.S. Pedersen, D.E. Otzen, Bacterial amphiphiles as amyloid inducers: Effect of Rhamnolipid and Lipopolysaccharide on FapC fibrillation, Biochimica et Biophysica Acta (BBA)-Proteins and Proteomics 1867(11) (2019) 140263.

[14] I. Capila, R.J. Linhardt, Heparin-protein interactions, Angewandte Chemie International Edition 41(3) (2002) 390-412.

[15] T. Hryszko, S. Brzosko, M. Mysliwiec, Low concentration of heparin used for permanent catheters canal locking is effective and diminishes the risk of bleeding, International urology and nephrology 45(3) (2013) 825-829.

[16] J. Hirsh, S.S. Anand, J.L. Halperin, V. Fuster, Mechanism of action and pharmacology of unfractionated heparin, Am Heart Assoc, 2001.

[17] R.M. Shanks, N.P. Donegan, M.L. Graber, S.E. Buckingham, M.E. Zegans, A.L. Cheung, G.A. O'Toole, Heparin stimulates Staphylococcus aureus biofilm formation, Infection and immunity 73(8) (2005) 45964606.

[18] S. Mishra, A.R. Horswill, Heparin mimics extracellular DNA in binding to cell surface-localized proteins and promoting Staphylococcus aureus biofilm formation, Msphere 2(3) (2017).

[19] C.J. Jones, S. Beni, J.F. Limtiaco, D.J. Langeslay, C.K. Larive, Heparin characterization: challenges and solutions, Annual review of analytical chemistry 4 (2011) 439-465. 
bioRxiv preprint doi: https//doi.org/10.1101/2021.03.07.434294; this version posted March 9, 2021. The copyright holder for this preprint (which was not certified by peer review) is the author/funder, who has granted bioRxiv a license to display the preprint in perpetuity. It is made available under aCC-BY-NC-ND 4.0 International license.

[20] A. Nitani, H. Muta, M. Adachi, M. So, K. Sasahara, K. Sakurai, E. Chatani, K. Naoe, H. Ogi, D. Hall, Heparin-dependent aggregation of hen egg white lysozyme reveals two distinct mechanisms of amyloid fibrillation, Journal of Biological Chemistry 292(52) (2017) 21219-21230.

[21] J.A. Cohlberg, J. Li, V.N. Uversky, A.L. Fink, Heparin and other glycosaminoglycans stimulate the formation of amyloid fibrils from $\alpha$-synuclein in vitro, Biochemistry 41(5) (2002) 1502-1511.

[22] A. Relini, S. De Stefano, S. Torrassa, O. Cavalleri, R. Rolandi, A. Gliozzi, S. Giorgetti, S. Raimondi, L. Marchese, L. Verga, Heparin strongly enhances the formation of $\beta 2$-microglobulin amyloid fibrils in the presence of type I collagen, Journal of Biological Chemistry 283(8) (2008) 4912-4920.

[23] S. Bourgault, J.P. Solomon, N. Reixach, J.W. Kelly, Sulfated glycosaminoglycans accelerate transthyretin amyloidogenesis by quaternary structural conversion, Biochemistry 50(6) (2011) 1001-1015.

[24] B. Klajnert, M. Cortijo-Arellano, M. Bryszewska, J. Cladera, Influence of heparin and dendrimers on the aggregation of two amyloid peptides related to Alzheimer's and prion diseases, Biochemical and biophysical research communications 339(2) (2006) 577-582.

[25] L. Whitmore, B.A. Wallace, Protein secondary structure analyses from circular dichroism spectroscopy: methods and reference databases, Biopolymers 89(5) (2008) 392-400.

[26] L. Whitmore, B.A. Wallace, DICHROWEB, an online server for protein secondary structure analyses from circular dichroism spectroscopic data, Nucleic Acids Res 32(Web Server issue) (2004) W668-73.

[27] J.G. Lees, A.J. Miles, F. Wien, B.A. Wallace, A reference database for circular dichroism spectroscopy covering fold and secondary structure space, Bioinformatics 22(16) (2006) 1955-1962.

[28] A. Bleem, G. Christiansen, D.J. Madsen, H. Maric, K. Strømgaard, J.D. Bryers, V. Daggett, R.L. Meyer, D.E. Otzen, Protein engineering reveals mechanisms of functional amyloid formation in Pseudomonas aeruginosa biofilms, Journal of molecular biology 430(20) (2018) 3751-3763.

[29] H. LeVine, 3rd, Thioflavine T interaction with synthetic Alzheimer's disease beta-amyloid peptides: detection of amyloid aggregation in solution, Protein science : a publication of the Protein Society 2(3) (1993) 404-10.

[30] G. Meisl, J.B. Kirkegaard, P. Arosio, T.C. Michaels, M. Vendruscolo, C.M. Dobson, S. Linse, T.P. Knowles, Molecular mechanisms of protein aggregation from global fitting of kinetic models, Nature protocols 11(2) (2016) 252-272.

[31] A. Munke, J. Persson, T. Weiffert, E. De Genst, G. Meisl, P. Arosio, A. Carnerup, C.M. Dobson, M. Vendruscolo, T.P.J. Knowles, S. Linse, Phage display and kinetic selection of antibodies that specifically inhibit amyloid self-replication, Proc Natl Acad Sci U S A 114(25) (2017) 6444-6449.

[32] C. Mansson, P. Arosio, R. Hussein, H.H. Kampinga, R.M. Hashem, W.C. Boelens, C.M. Dobson, T.P. Knowles, S. Linse, C. Emanuelsson, Interaction of the molecular chaperone DNAJB6 with growing amyloidbeta 42 (Abeta42) aggregates leads to sub-stoichiometric inhibition of amyloid formation, J Biol Chem 289(45) (2014) 31066-76.

[33] T.C.T. Michaels, A. Saric, G. Meisl, G.T. Heller, S. Curk, P. Arosio, S. Linse, C.M. Dobson, M. Vendruscolo, T.P.J. Knowles, Thermodynamic and kinetic design principles for amyloid-aggregation inhibitors, Proc Natl Acad Sci U S A 117(39) (2020) 24251-24257.

[34] A.R. Fersht, Structure and mechanism in protein science. A guide to enzyme catalysis and protein folding, Freeman \& Co., New York, 1999.

[35] D.E. Otzen, Protein-surfactant interactions: a tale of many states, Biochim. Biophys. Acta 1814 (2011) 562-591.

[36] P. Marinelli, I. Pallares, S. Navarro, S. Ventura, Dissecting the contribution of Staphylococcus aureus $\alpha$ phenol-soluble modulins to biofilm amyloid structure, Scientific reports 6(1) (2016) 34552.

[37] E. Tayeb-Fligelman, O. Tabachnikov, A. Moshe, O. Goldshmidt-Tran, M.R. Sawaya, N. Coquelle, J.P. Colletier, M. Landau, The cytotoxic Staphylococcus aureus PSM $\alpha 3$ reveals a cross- $\alpha$ amyloid-like fibril, 355(6327) (2017) 831-833.

[38] E. Tayeb-Fligelman, N. Salinas, O. Tabachnikov, M. Landau, Staphylococcus aureus PSM $\alpha 3$ Cross- $\alpha$ Fibril Polymorphism and Determinants of Cytotoxicity, Structure (London, England : 1993) 28(3) (2020) 301-

313.e6. 
bioRxiv preprint doi: https://doi.org/10.1101/2021.03.07.434294 this version posted March 9, 2021. The copyright holder for this preprint (which was not certified by peer review) is the author/funder, who has granted bioRxiv a license to display the preprint in perpetuity. It is made available under aCC-BY-NC-ND 4.0 International license.

[39] T.P. Hopp, K.R. Woods, Prediction of protein antigenic determinants from amino acid sequences, Proceedings of the National Academy of Sciences 78(6) (1981) 3824-3828.

[40] A.M. Forson, H.C. van der Mei, J. Sjollema, Impact of solid surface hydrophobicity and micrococcal nuclease production on Staphylococcus aureus Newman biofilms, Scientific Reports 10(1) (2020) 12093.

[41] T. Baba, T. Bae, O. Schneewind, F. Takeuchi, K. Hiramatsu, Genome sequence of Staphylococcus aureus strain Newman and comparative analysis of staphylococcal genomes: polymorphism and evolution of two major pathogenicity islands, J Bacteriol 190(1) (2008) 300-10.

[42] G.Y. Cheung, H.-S. Joo, S.S. Chatterjee, M. Otto, Phenol-soluble modulins-critical determinants of staphylococcal virulence, FEMS microbiology reviews 38(4) (2014) 698-719.

[43] M. Otto, Staphylococcal biofilms, Gram-Positive Pathogens (2019) 699-711.

[44] S.B. Nielsen, P. Yde, L. Giehm, S. Sundbye, G. Christiansen, J. Mathiesen, M.H. Jensen, P.H. Jensen, D.E. Otzen, Multiple roles of heparin in the aggregation of p25 $\alpha$, J Mol Biol 421(4-5) (2012) 601-15.

[45] N.N. Jha, A. Anoop, S. Ranganathan, G.M. Mohite, R. Padinhateeri, S.K. Maji, Characterization of amyloid formation by glucagon-like peptides: role of basic residues in heparin-mediated aggregation, Biochemistry 52(49) (2013) 8800-8810.

[46] N. Motamedi-Shad, E. Monsellier, F. Chiti, Amyloid formation by the model protein muscle acylphosphatase is accelerated by heparin and heparan sulphate through a scaffolding-based mechanism, Journal of biochemistry 146(6) (2009) 805-814.

[47] J. McLaurin, T. Franklin, X. Zhang, J. Deng, P.E. Fraser, Interactions of Alzheimer amyloid- $\beta$ peptides with glycosaminoglycans: Effects on fibril nucleation and growth, European journal of biochemistry 266(3) (1999) 1101-1110.

[48] A.D. Cardin, H. Weintraub, Molecular modeling of protein-glycosaminoglycan interactions, Arteriosclerosis: An Official Journal of the American Heart Association, Inc. 9(1) (1989) 21-32.

[49] F. Noborn, P. O'Callaghan, E. Hermansson, X. Zhang, J.B. Ancsin, A.M. Damas, I. Dacklin, J. Presto, J. Johansson, M.J. Saraiva, Heparan sulfate/heparin promotes transthyretin fibrillization through selective binding to a basic motif in the protein, Proceedings of the National Academy of Sciences 108(14) (2011) 5584-5589.

[50] E. Tayeb-Fligelman, N. Salinas, O. Tabachnikov, M. Landau, Staphylococcus aureus PSM $\alpha 3$ Cross- $\alpha$ Fibril Polymorphism and Determinants of Cytotoxicity, Structure 28(3) (2020) 301-313. e6.

[51] N. Salinas, J.-P. Colletier, A. Moshe, M. Landau, Extreme amyloid polymorphism in Staphylococcus aureus virulent PSM $\alpha$ peptides, Nature communications 9(1) (2018) 1-9.

[52] S.-f. Shi, J.-f. Jia, X.-k. Guo, Y.-p. Zhao, D.-s. Chen, Y.-y. Guo, X.-I. Zhang, Reduced Staphylococcus aureus biofilm formation in the presence of chitosan-coated iron oxide nanoparticles, International journal of nanomedicine 11 (2016) 6499.

[53] R.P. Carlson, R. Taffs, W.M. Davison, P.S. Stewart, Anti-biofilm properties of chitosan-coated surfaces, Journal of Biomaterials Science, Polymer Edition 19(8) (2008) 1035-1046.

[54] M. So, Y. Hata, H. Naiki, Y. Goto, Heparin-induced amyloid fibrillation of $\beta(2)$-microglobulin explained by solubility and a supersaturation-dependent conformational phase diagram, Protein science : a publication of the Protein Society 26(5) (2017) 1024-1036.

[55] J.A. Cohlberg, J. Li, V.N. Uversky, A.L. Fink, Heparin and other glycosaminoglycans stimulate the formation of amyloid fibrils from alpha-synuclein in vitro, Biochemistry 41(5) (2002) 1502-11. 
bioRxiv preprint doi: https://doi.org/10.1101/2021.03 07.434294. this version posted March 9 2021. The copyright holder for this preprint (which was not certified by peer review) is the author/funder, who has granted bioRxiv a license to display the preprint in perpetuity. It is made available under aCC-BY-NC-ND 4.0 International license.

\section{Figure legends:}

Figure 1: Thioflavin $\mathrm{T}$ time curves for PSM aggregation under quiescent conditions in the absence and presence of different heparin concentrations. The data depict representatives of triplicate experiments. PSMa1-4 and PSMb2 were incubated at $0.25 \mathrm{mg} / \mathrm{mL}$ PSM with the indicated range of heparin concentrations. PSM $\beta 1$ and $\delta$-toxin were incubated at 0.025 and $0.3 \mathrm{mg} / \mathrm{mL}$ peptide, respectively.

Figure 2: Plots of different composite rate constants (obtained from fits to PSM aggregation data) versus heparin concentration. (A) PSM $\alpha$ 1, (B) PSM $\alpha 3$, (C) PSM $\beta 1$ at low heparin concentrations, (D) PSM $\beta 1$ at high heparin concentrations, (E) PSM $\beta 2$ (log-log plot), (F) $\delta$-toxin (showing poor linear correlation with heparin concentration).

Figure 3: Structural comparison of fibrils formed by different PSMs in the absence and presence of heparin. (A) Synchrotron radiation (SR) Far UV-CD spectra of all PSM fibrils incubated with or without heparin. Fibrillated samples were centrifuged (13k rpm for $30 \mathrm{~min})$, supernatant discarded, and the pellet resuspended in the same volume of milliQ water, (B) Deconvolution of the SRCD spectra from panel A, (C) FTIR spectroscopy of the amide I' region (1600-1700 $\mathrm{cm}^{-1}$ ) of PSM fibrils formed in the absence and presence of heparin. PSM $\alpha 1$, PSM $\alpha 4$, PSM $\beta 1$ and PSM $\beta 2$ show a peak at $1625 \mathrm{~cm}^{-1}$ corresponding to rigid amyloid fibrils. In contrast, PSM $\alpha 3$ and $\delta$-toxin show main peaks at and $1655 \mathrm{~cm}^{-1}$, with the latter indicating more disordered fibrils, (D) Deconvolution of the FTIR spectra from panel C.

Figure 4: Electron microscope images of fibrils formed from PSMs in the absence and presence of heparin. TEM micrographs of (A) PSM $\alpha 1$ without heparin, (B) PSM $\alpha 1$ with $3 \mu \mathrm{g} / \mathrm{mL}$ heparin, (C) PSM $\alpha 3$ without heparin, (D) PSM $\alpha 3$ with $40 \mu \mathrm{g} / \mathrm{mL}$ heparin, (E) PSM $\alpha 4$ without heparin, (F) PSM $\alpha 4$ with $20 \mu \mathrm{g} / \mathrm{mL}$ heparin, (G) PSM $\beta 1$ without heparin, (H) PSM $\beta 1$ with $40 \mu \mathrm{g} / \mathrm{mL}$ heparin (I) PSM $\beta 2$ without heparin, (J) PSM $\beta 2$ with $1 \mathrm{mg} / \mathrm{ml}$ heparin (K) $\delta$-toxin without heparin and $(\mathrm{L}) \delta$-toxin with $1 \mathrm{mg} / \mathrm{ml}$ heparin. Note that scale bars vary between panels.

Figure 5: Interaction of fluorescein-labeled heparin with different PSM peptides displayed on a peptide array. Data provides signal intensity from different PSM sequences interacting with heparin. Full PSM sequences are provided in each panel. (A) PSM $\alpha 1$, (B) PSM $\alpha 2$, (C) PSM $\alpha 3$, (D) PSM $\alpha 4$, (E) $\delta$-toxin, (F) PSM $\beta 1$, (G) PSM $\beta 2$.

For each spot, the number on the $\mathrm{x}$-axis gives the residue position in the intact PSM sequence, corresponding to the starting residue in the spot's 10 -mer peptide. 
Figure 6: Interaction of fluorescein-labeled heparin with peptide-array peptide sequences designed for Ala scans of different PSMs. Data provides signal intensity from different Ala-scanned PSM sequences interacting with heparin. Each PSM peptide was divided into 10-residue sequences, each with their own color; in each peptide, positions were individually replaced by Ala from left to right. "wt" is the initial peptide before starting Ala scan. Each letter on the $\mathrm{x}$ axis show the residue that is replaced by Ala, (A) PSM $\alpha 1$, (B) PSM $\alpha 2$, (C) PSM $\alpha 3$, (D) PSM $\alpha 4$, (E) $\delta$-toxin, (F) PSM $\beta 1,(\mathrm{G})$ PSM $\beta 2$.

Figure 7: Biofilm formation in the presence of heparin. $A_{s} / A_{c}$ is the absorbance of samples at $590 \mathrm{~nm}$ (indicative of the amount of biofilm produced) in the presence of heparin divided by absorbance of the control (same strain grown in the absence of heparin). Mean $\pm \mathrm{SD}, \mathrm{n}=3, * p<0.05, * * p<0.002, * * * p<0.0002, * * * * p<0.0001$. 


\section{Figure 1}
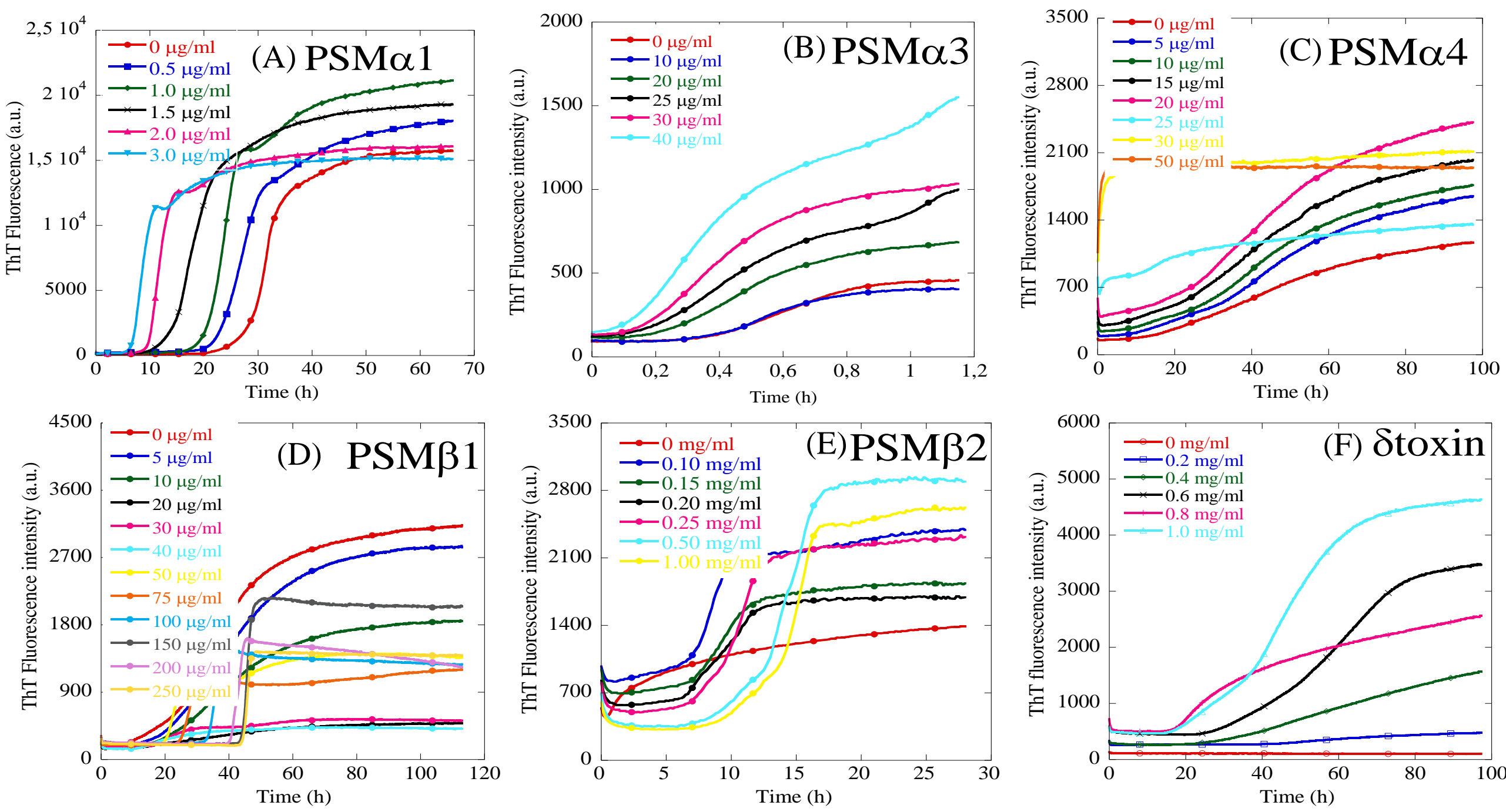

Figure 1: Thioflavin $T$ time curves for PSM aggregation under quiescent conditions in the absence and presence of different heparin concentrations. The data depict representatives of triplicate experiments. PSM $\alpha 1-4$ and PSM $\beta 2$ were incubated at $0.25 \mathrm{mg} / \mathrm{mL} \mathrm{PSM} \mathrm{with}$ the indicated range of heparin concentrations. PSM $\beta 1$ and $\delta$-toxin were incubated at 0.025 and $0.3 \mathrm{mg} / \mathrm{mL}$ peptide, respectively. 


\section{Figure 2}
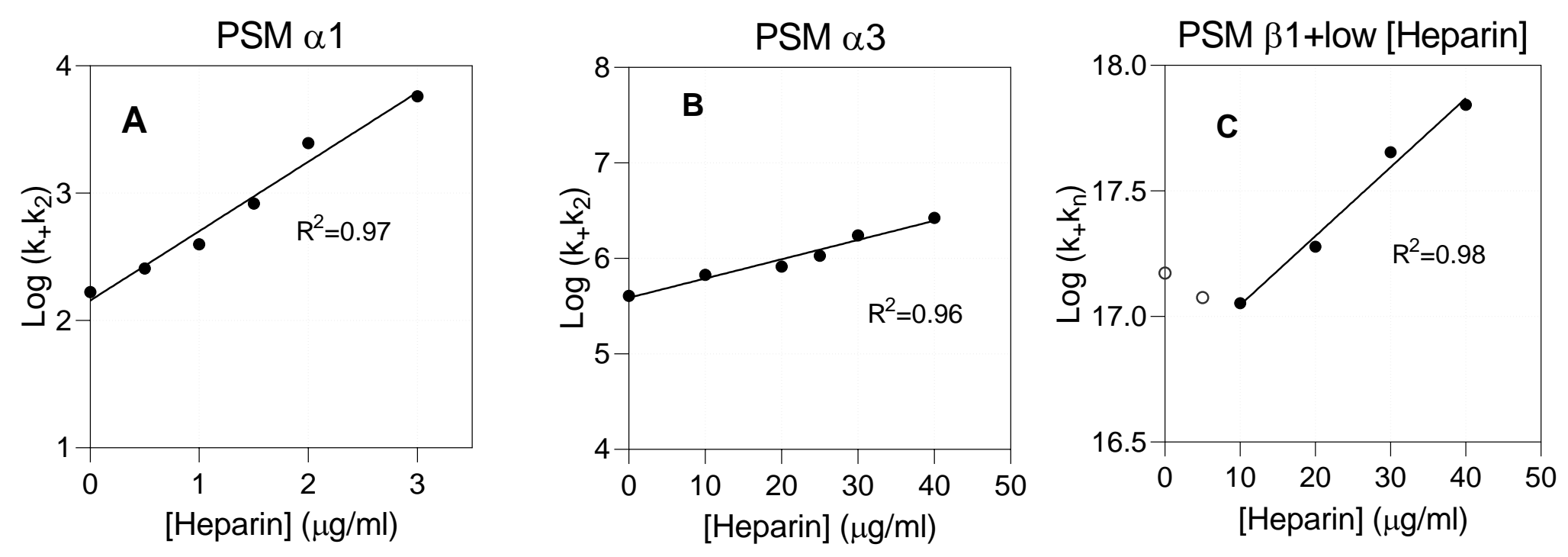

Figure 2: Plots of different composite rate constants (obtained from fits to PSM aggregation data) versus heparin concentration.
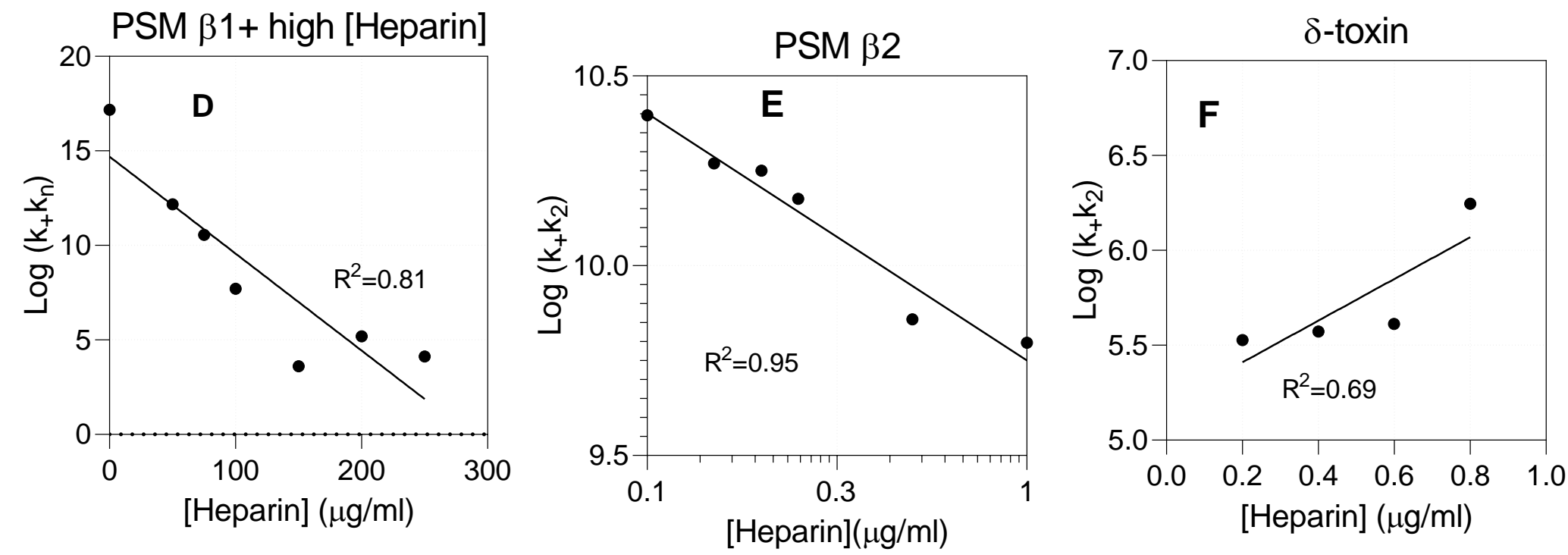

(A) PSM $\alpha 1$.

(B) PSM $\alpha 3$.

(C) PSM $\beta 1$ at low heparin concentrations.

(D) PSM $\beta 1$ at high heparin concentrations.

(E) PSM $\beta 2$ (log-log plot).

(F) $\delta$-toxin (showing poor linear correlation with heparin concentration). 


\section{Figure 3}
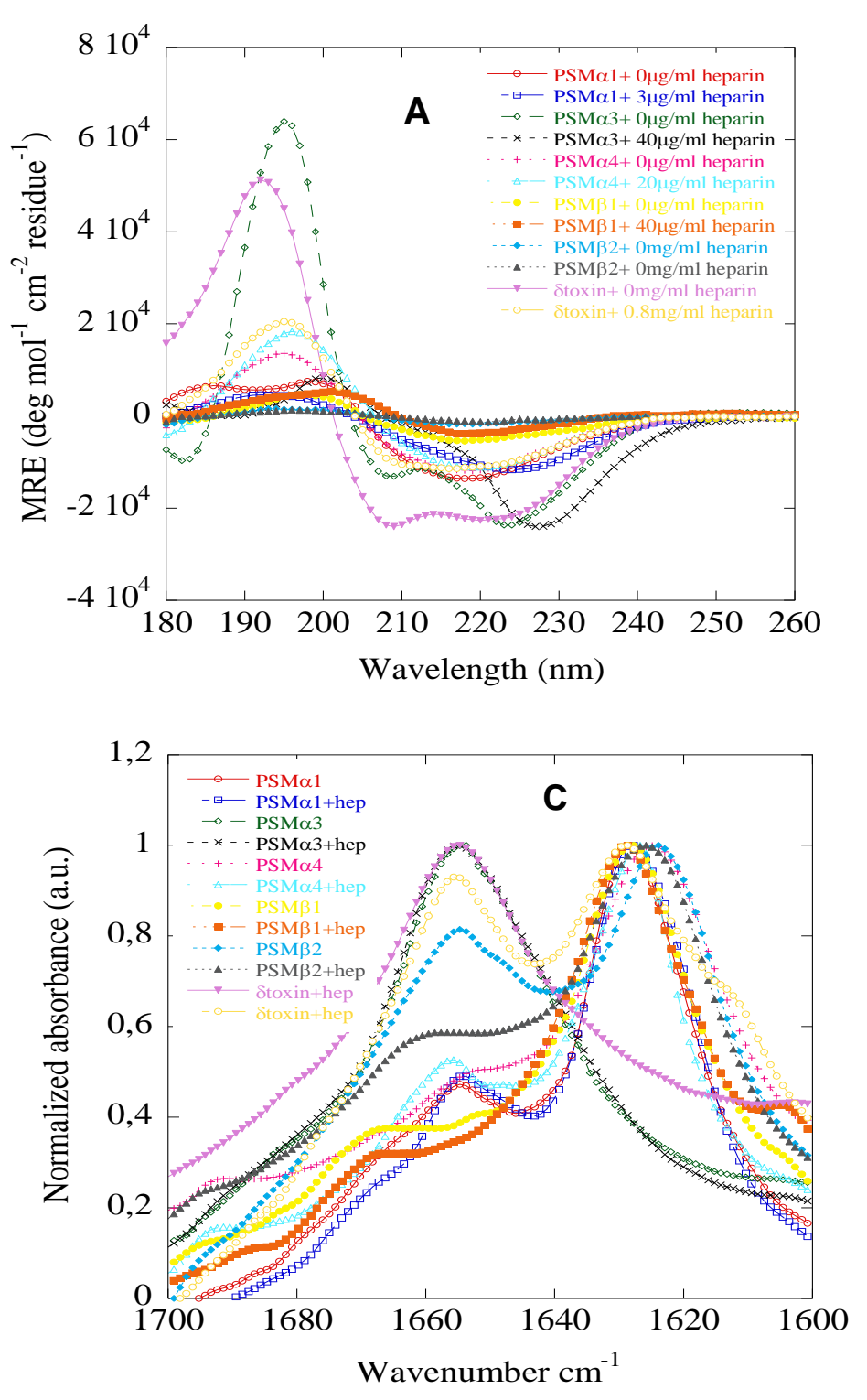
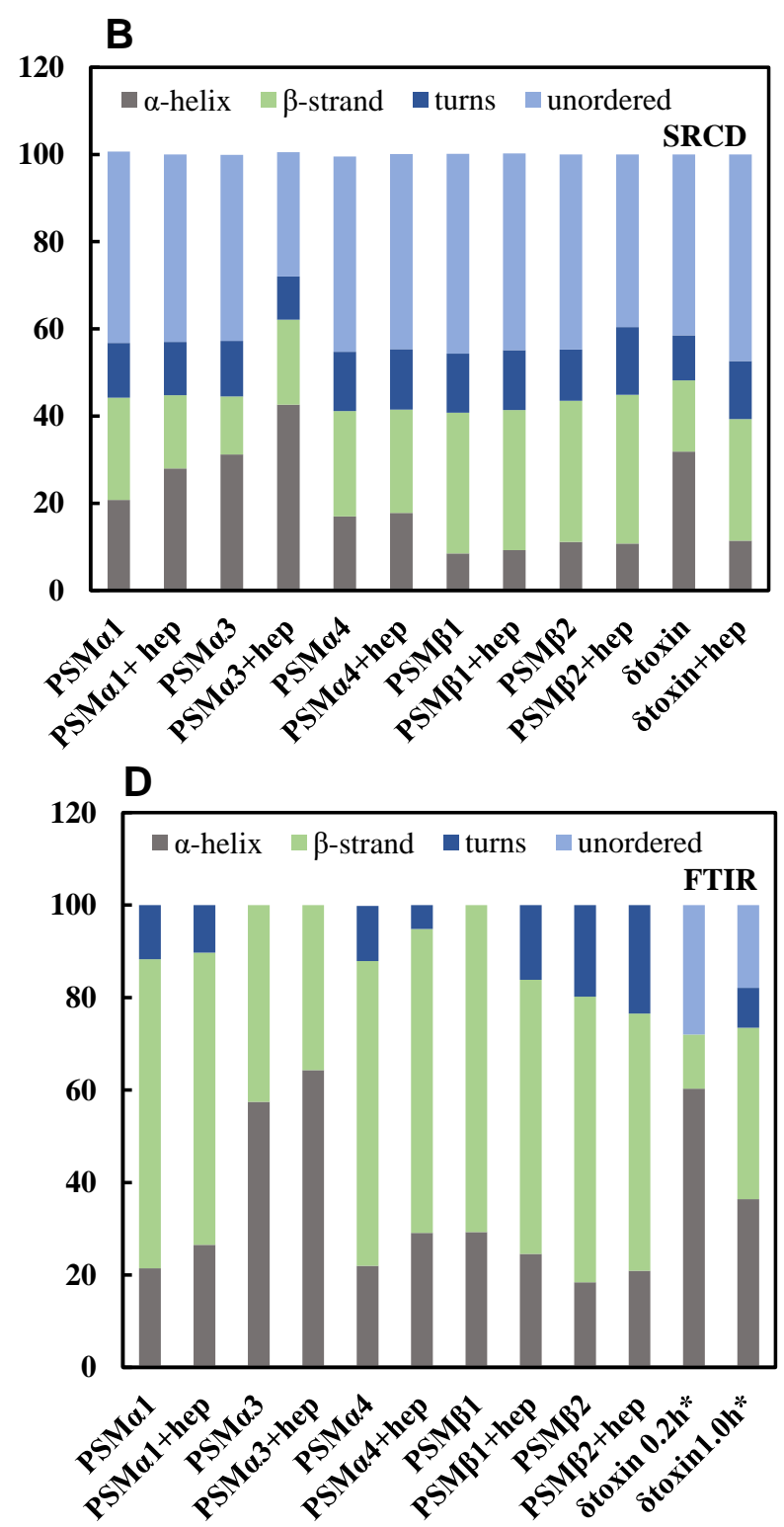

Figure 3: Structural comparison of fibrils formed by different PSMs in the absence and presence of heparin.

(A) Synchrotron radiation (SR) Far UV-CD spectra of all PSM fibrils incubated with or without heparin. Fibrillated samples were centrifuged (13k rpm for $30 \mathrm{~min}$ ), supernatant discarded, and the pellet resuspended in the same volume of milliQ water. (B) Deconvolution of the SRCD spectra from panel A.

(C) FTIR spectroscopy of the amide I' region $\left(1600-1700 \mathrm{~cm}^{-1}\right)$ of PSM fibrils formed in the absence and presence of heparin. PSM $\alpha 1$, PSM $\alpha 4$, PSM $\beta 1$ and PSM $\beta 2$ show a peak at $1625 \mathrm{~cm}^{-1}$ corresponding to rigid amyloid fibrils. In contrast, PSM $\alpha 3$ and $\delta$-toxin show main peaks at and $1655 \mathrm{~cm}^{-1}$, with the latter indicating more disordered fibrils.

(D) Deconvolution of the FTIR spectra from panel C. 


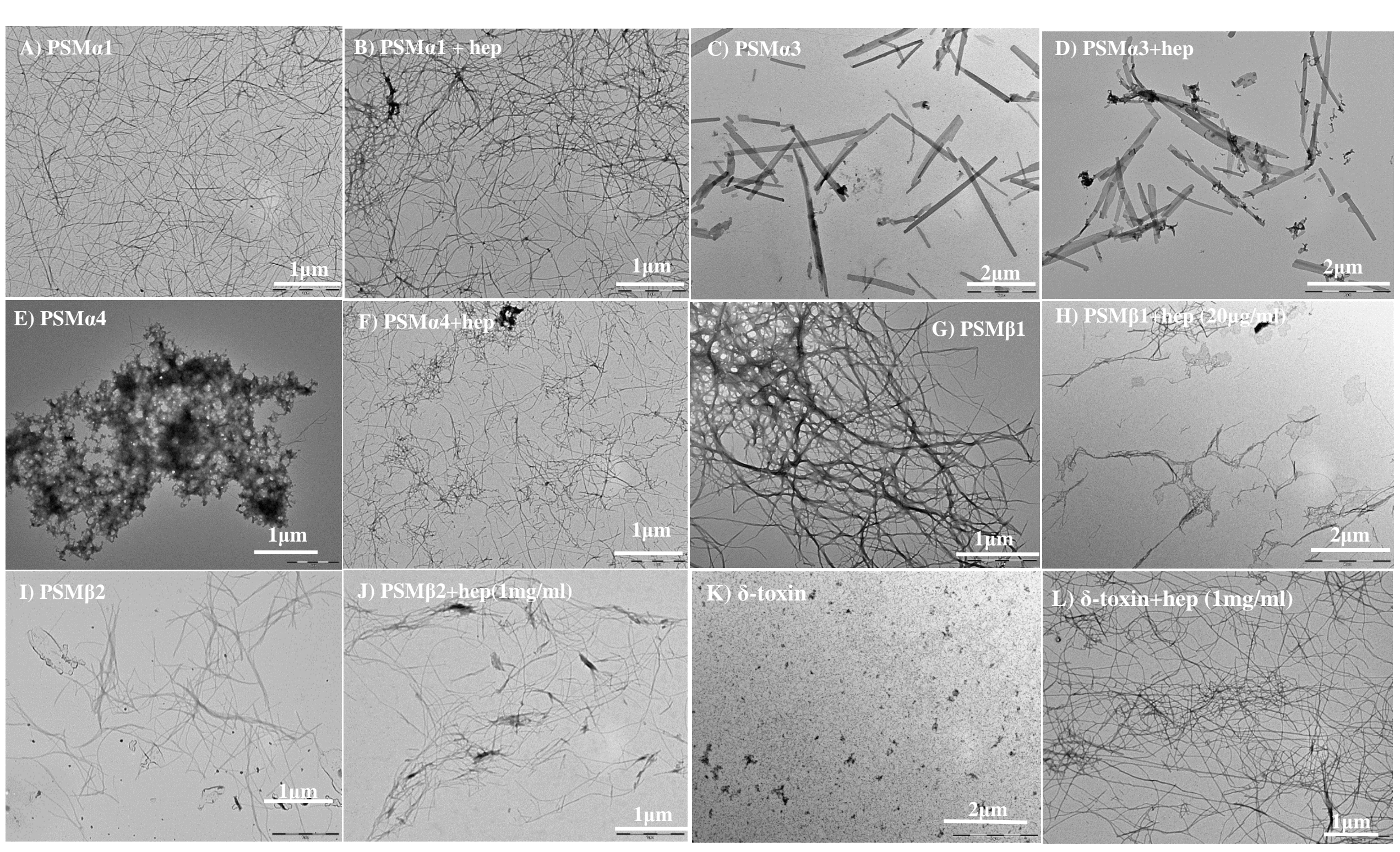

\section{Figure 4}

Figure 4: Electron microscope images of fibrils formed from PSMs in the absence and presence of heparin. TEM micrographs of (A) PSM $\alpha 1$ without heparin, (B) PSM $\alpha 1$ with $3 \mu \mathrm{g} / \mathrm{mL}$ heparin, (C) PSM $\alpha 3$ without heparin, (D) PSM $\alpha 3$ with $40 \mu \mathrm{g} / \mathrm{mL}$ heparin, (E) PSM $\alpha 4$ without heparin, (F) PSM $\alpha 4$ with $20 \mu \mathrm{g} / \mathrm{mL}$ heparin, (G) PSM $\beta 1$ without heparin, (H) PSM $\beta 1$ with $40 \mu \mathrm{g} / \mathrm{mL}$ heparin (I) PSM $\beta 2$ without heparin, (J) PSM $\beta 2$ with $1 \mathrm{mg} / \mathrm{ml}$ heparin $(\mathrm{K}) \delta$-toxin without heparin and $(\mathrm{L}) \delta$-toxin with $1 \mathrm{mg} / \mathrm{ml}$ heparin. Note that scale bars vary between panels. 

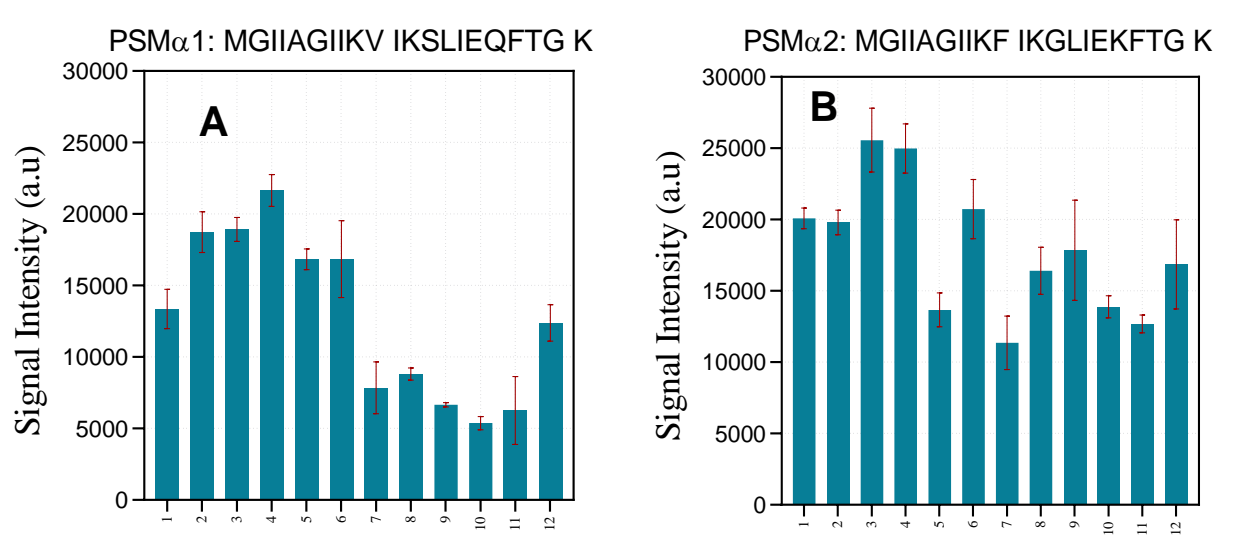

PSM $\alpha 1$ - Sequences (starting residue)

$\mathrm{PSM} \alpha 2$ - Sequences (starting residue)

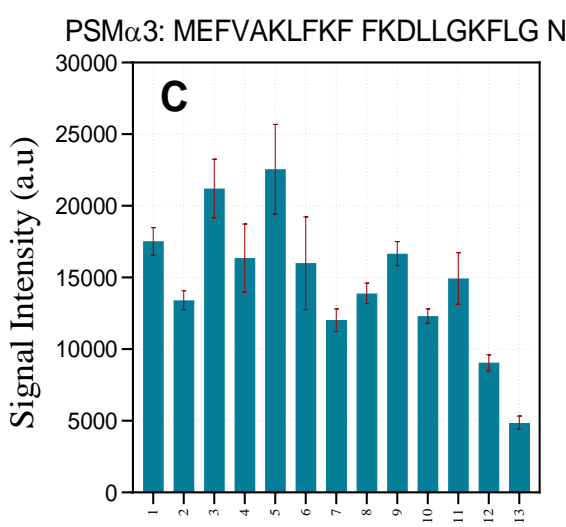

PSM $\alpha 3$ - Sequences (starting residue)
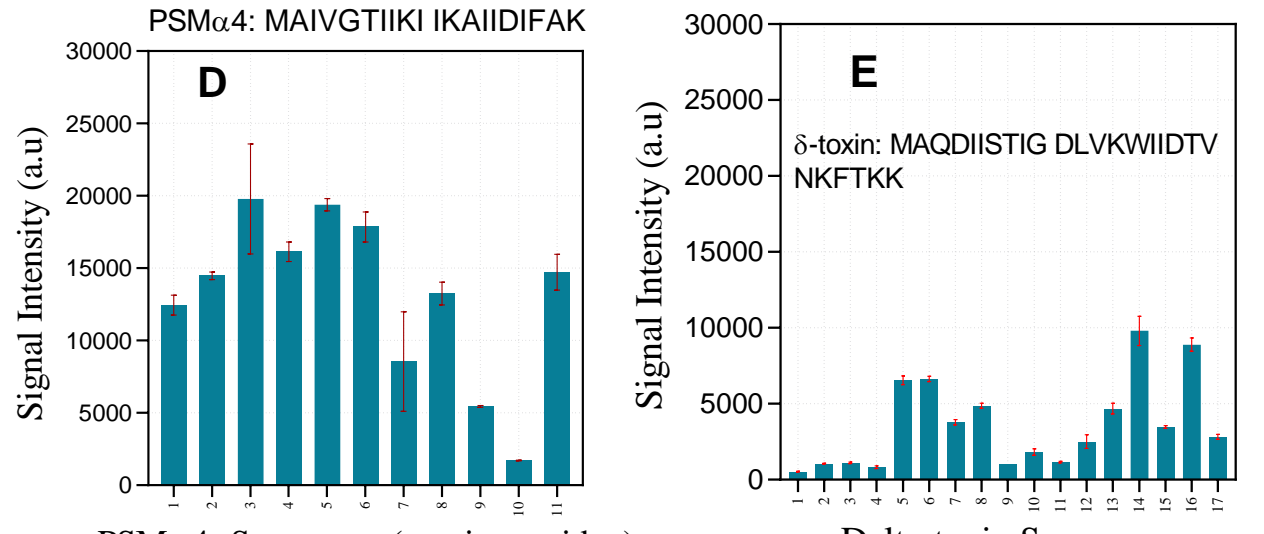

Delta-toxin Sequences

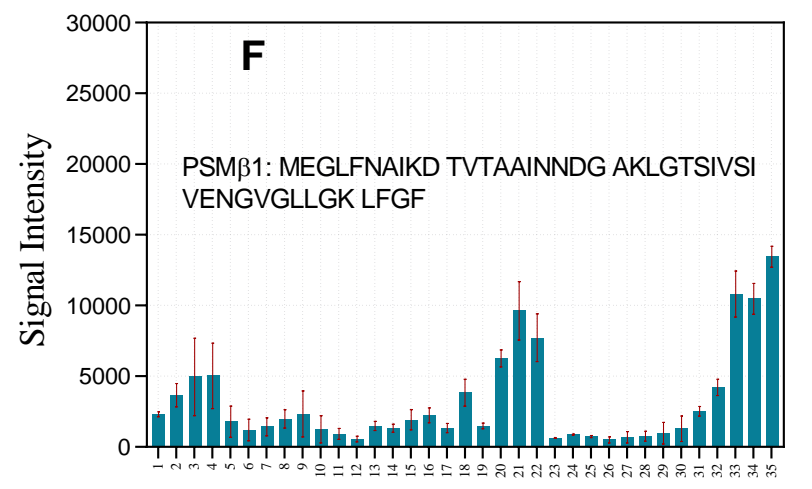

PSM $\beta 1$ - Sequences

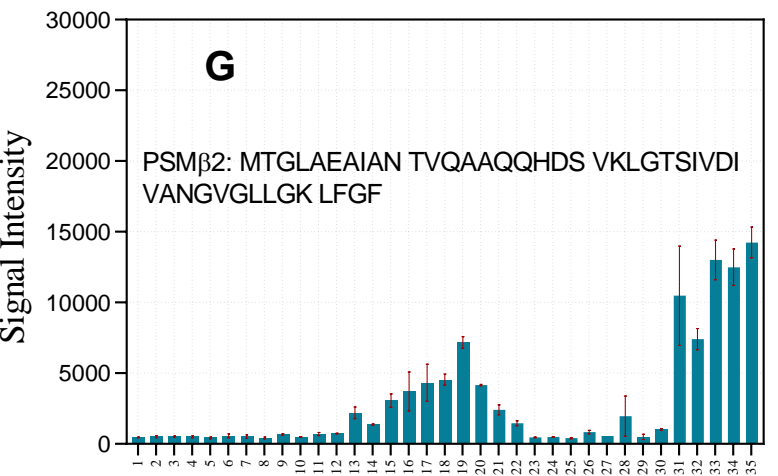

PSM $\beta 2$ - Sequences

\section{Figure 5}

Figure 5: Interaction of fluorescein-labeled heparin with different PSM peptides displayed on a peptide array. Data provides signal intensity from different PSM sequences interacting with heparin. Full PSM sequences are provided in each panel.
(A) PSM $\alpha 1$.
(B) PSM $\alpha 2$.
(C) PSM $\alpha 3$.
(D) PSM $\alpha$.
(E) $\delta$-toxin.
(F) PSM $\beta 1$.
(G) PSM $\beta 2$.

For each spot, the number on the $\mathrm{x}$-axis gives the residue position in the intact PSM sequence, corresponding to the starting residue in the spot's 10-mer peptide. 

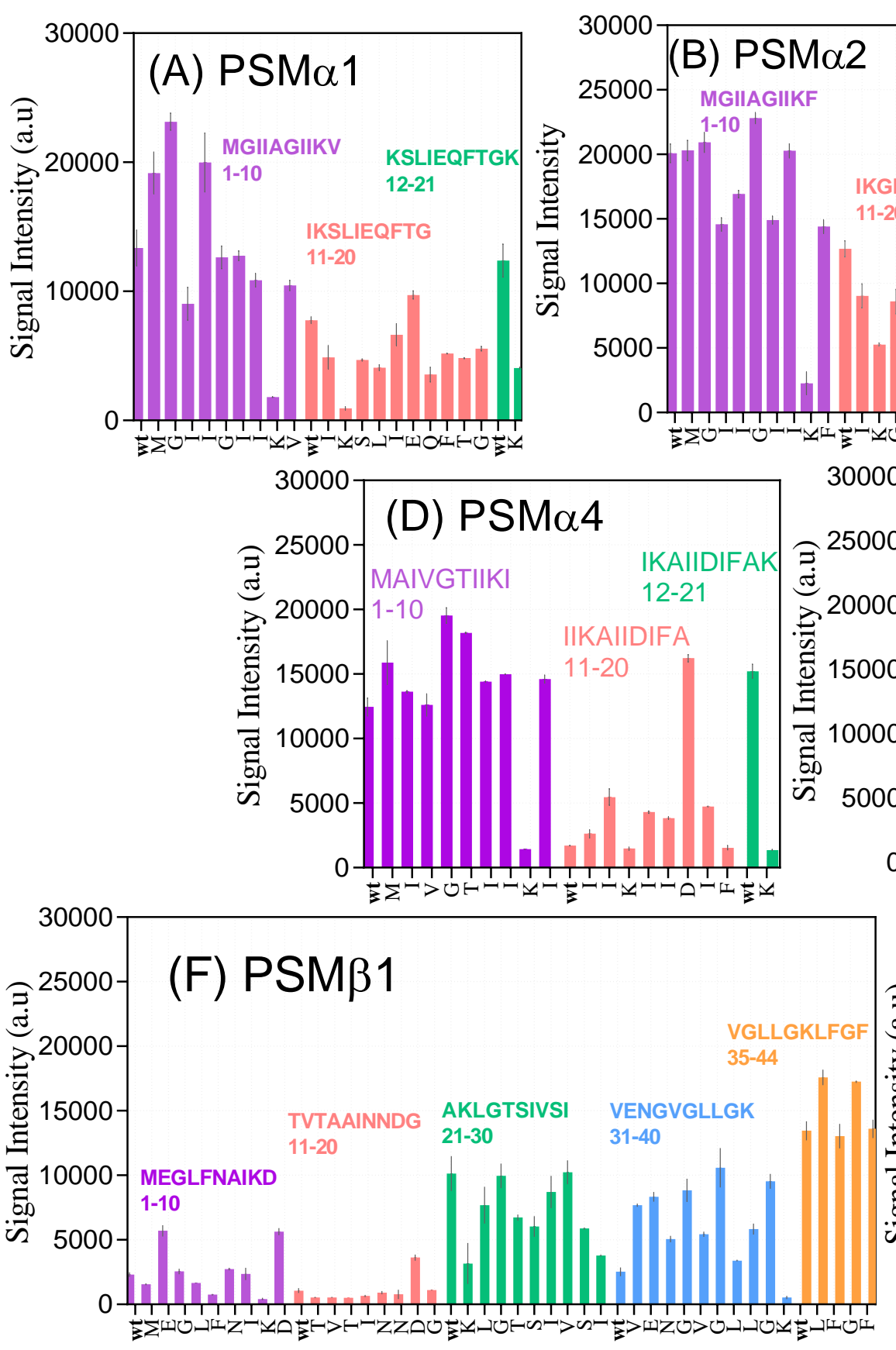
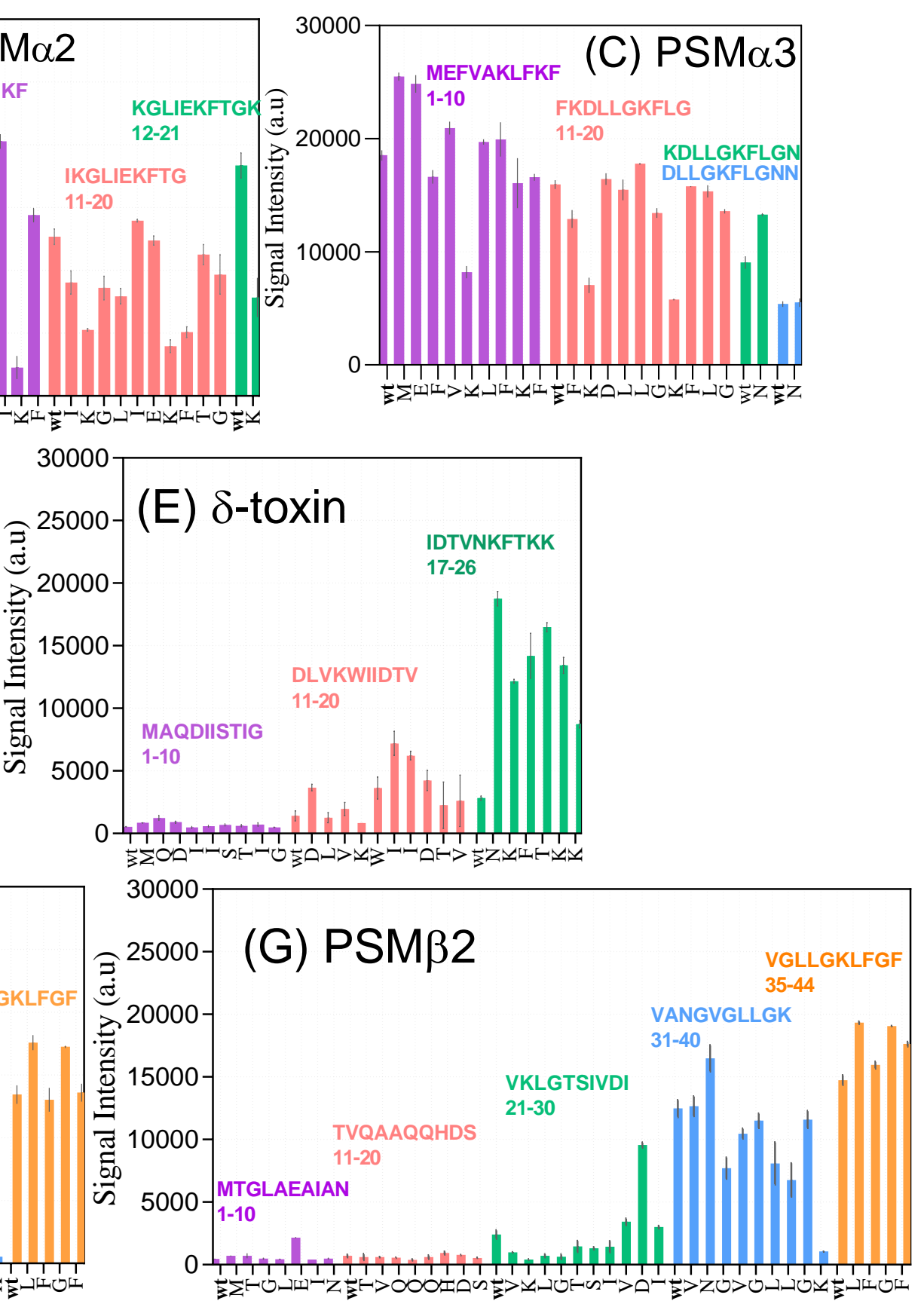

Figure 6: Interaction of fluorescein-labeled heparin with peptide-array peptide sequences designed for Ala scans of different PSMs.

Data provides signal intensity from different Ala-scanned PSM sequences interacting with heparin. Each PSM peptide was divided into 10-residue sequences, each with their own color; in each peptide, positions were individually replaced by Ala from left to right. "wt" is the initial peptide before starting Ala scan. Each letter on the $\mathrm{x}$-axis show the residue that is replaced by Ala.
(A) PSM $\alpha 1$
(B) PSM $\alpha 2$.
(C) PSM $\alpha 3$
(D) PSM $\alpha 4$
(E) $\delta$-toxin.
(F) PSM $\beta 1$.
(G) PSM $\beta 2$. 


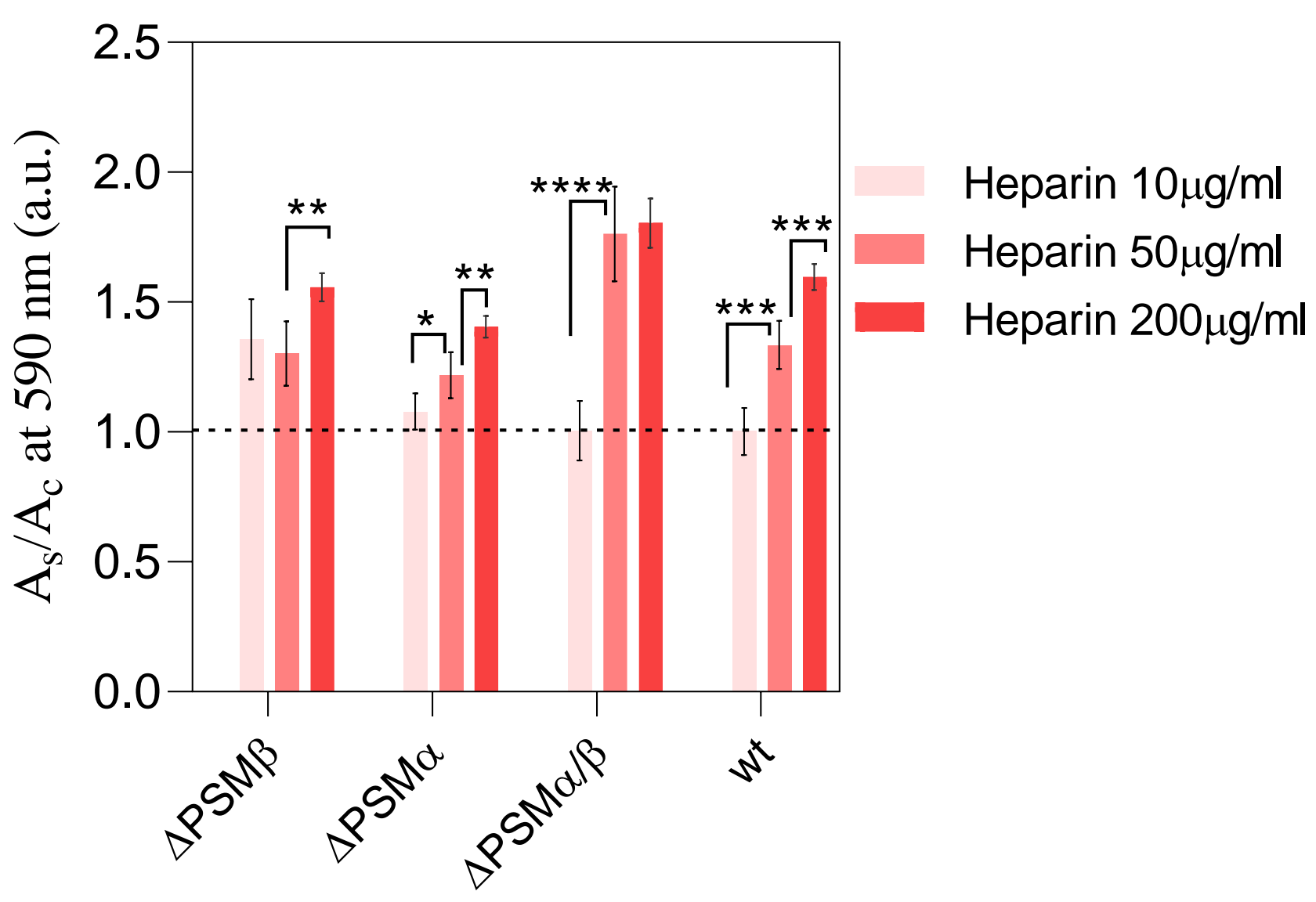

Figure 7: Biofilm formation in the presence of heparin. $A_{s} / A_{c}$ is the absorbance of samples at 590 $\mathrm{nm}$ (indicative of the amount of biofilm produced) in the presence of heparin divided by absorbance of the control (same strain grown in the absence of heparin). Mean $\pm \mathrm{SD}, \mathrm{n}=3, * p<0.05, * * p<$ $0.002, * * * p<0.0002, * * * * p<0.0001$. 


\section{Supplementary Information}

Heparin promotes fibrillation of most phenol soluble modulin peptides from S. aureus: a possible strengthening of the bacterial biofilm

Zahra Najarzadeh, Masihuz Zaman, Vita Serekaité, Kristian Strømgaard, Maria Andreasen and Daniel E. Otzen 

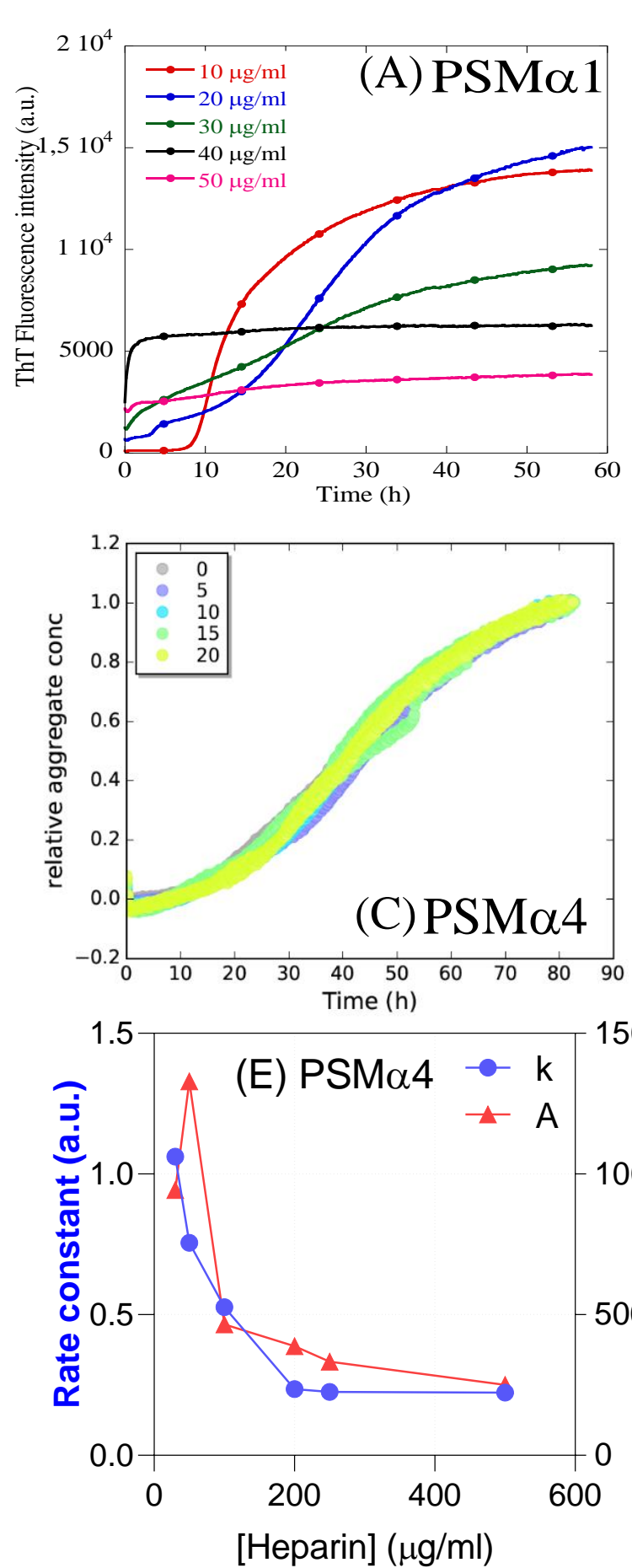
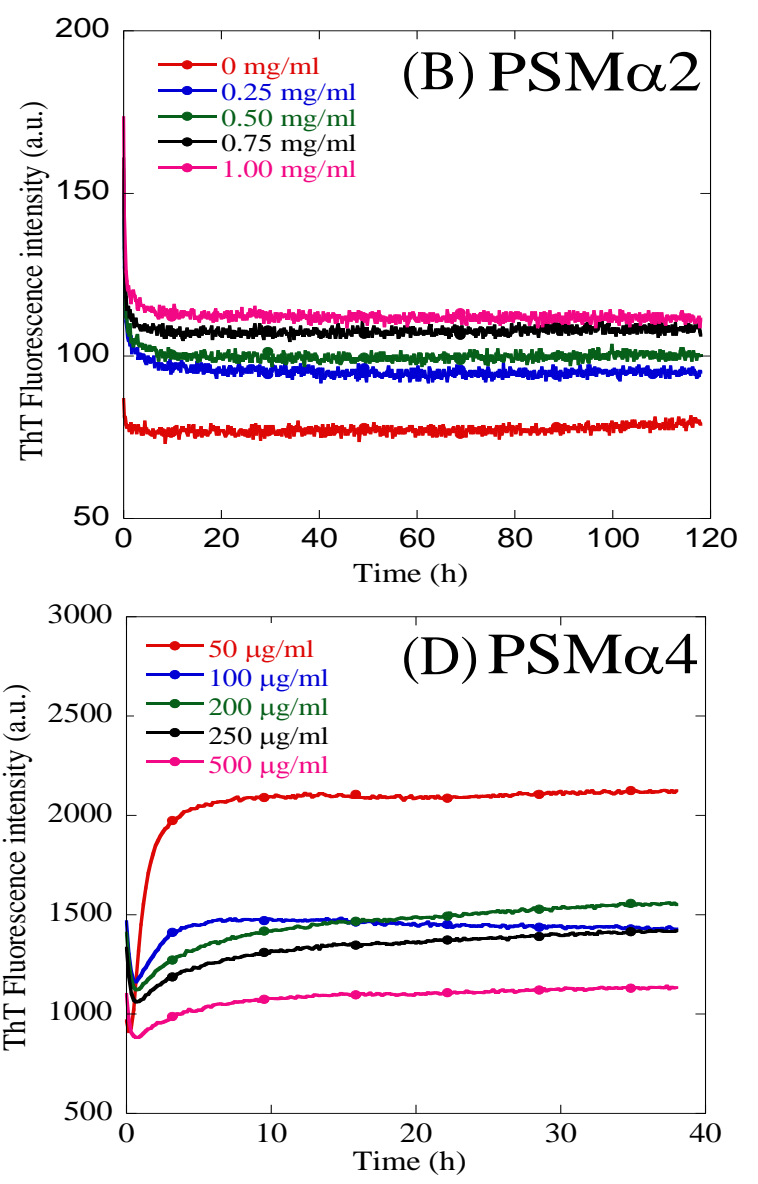

1500

250

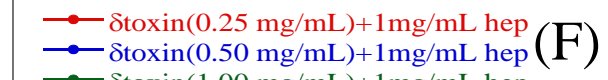
$\because-1 \mathrm{mg} / \mathrm{ml}$ heparin + DMSO

000

00

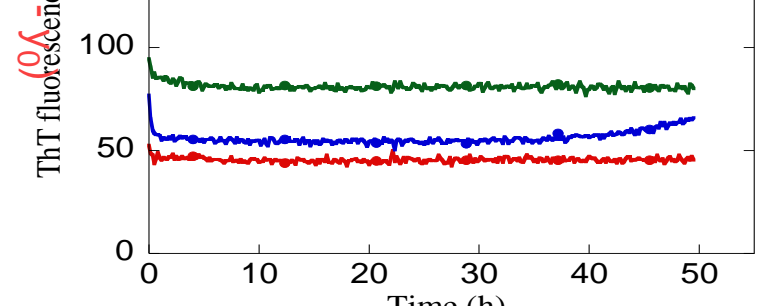

\section{Figure S1}

Figure S1: Effect of heparin concentration on PSMs fibrillation kinetics under quiescent conditions.

(A) $0.25 \mathrm{mg} / \mathrm{mL}$ PSM $\alpha 1$ with $10-50 \mu \mathrm{g} / \mathrm{mL}$ heparin.

(B) $0.25 \mathrm{mg} / \mathrm{mL}$ PSM $\alpha 2$ with $0-1 \mathrm{mg} / \mathrm{mL}$ heparin.

(C) Normalized ThT-curve for PSM $\alpha 4$ incubated with $0-20 \mu \mathrm{g} / \mathrm{ml}$ heparin.

(D) $0.25 \mathrm{mg} / \mathrm{mL}$ PSM $\alpha 4$ with $50-250 \mu \mathrm{g} / \mathrm{mL}$ heparin.

(E) Kinetic parameters for PSMa4 versus heparin concentration. Data for $30-500 \mu \mathrm{g} / \mathrm{mL}$ heparin in panel $\mathrm{D}$ were fitted with an exponential decay to yield rate constant $k$ and amplitude $A$.

(F) $\quad 0-1 \mathrm{mg} / \mathrm{ml}$ monomeric $\delta$-toxin in presence of 1 $\mathrm{mg} / \mathrm{ml}$ heparin. Data are representatives of triplicate experiments. 


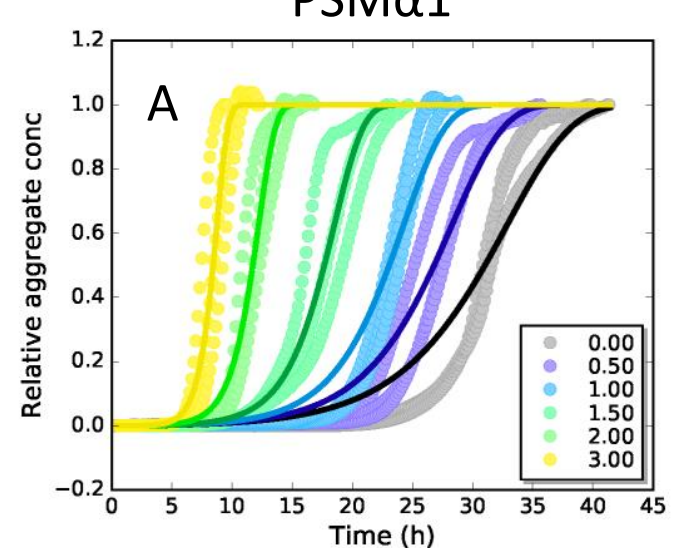

PSM $\beta 1+$ low heparin conc.

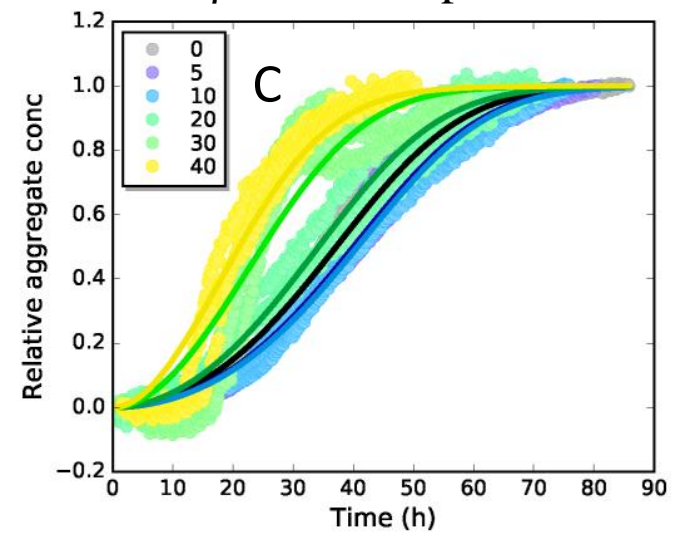

PSM $\beta 2$

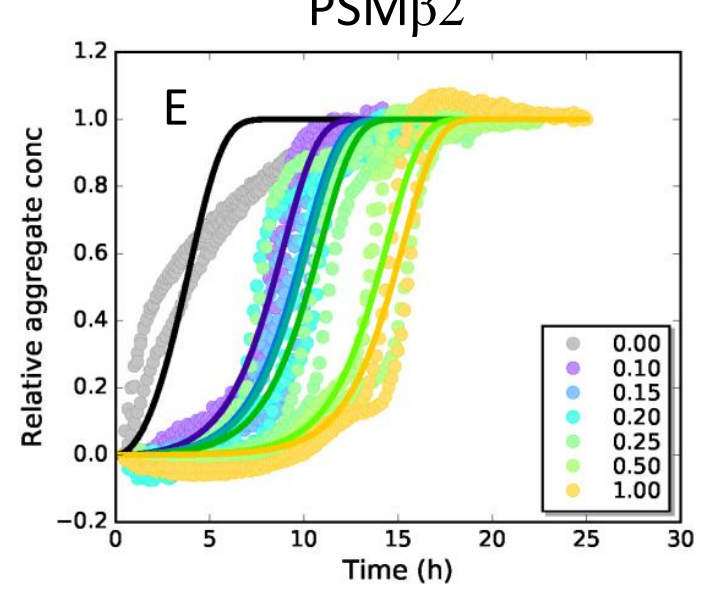

Figure S2

Figure S2: Fitting of aggregation kinetic data for PSM peptides in the presence of heparin using Amylofit. The heparin concentration in $\mu \mathrm{g} / \mathrm{mL}$ is indicated for each curve, all data fitted to a secondary nucleation dominated model using global constants: $\mathrm{n}_{\mathrm{c}}, \mathrm{n}_{2}, \mathrm{k}_{+} \mathrm{k}_{\mathrm{n}}$, individual fit: $\mathrm{k}_{+} \mathrm{k}_{2}$ (for PSM $\beta 1$ : individual fit: $\mathrm{k}_{+} \mathrm{k}_{\mathrm{n}}$ and global constant $\mathrm{k}_{+} \mathrm{k}_{\mathrm{n}}$ )

(A) Fitting of PSM $\alpha 1$ kinetic data at $0.25 \mathrm{mg} / \mathrm{mL}$ PSM $\alpha 1$ in the presence of 0-3 $\mu \mathrm{g} / \mathrm{mL}$ heparin.

(B) Fitting of PSM $\alpha 3$ kinetic data at $0.25 \mathrm{mg} / \mathrm{mL}$ PSM $\alpha 3$ in the presence of $0-40 \mu \mathrm{g} / \mathrm{mL}$ heparin.

(C) Fitting of PSM $\beta 1$ kinetic data at $0.025 \mathrm{mg} / \mathrm{mL}$ PSM $\beta 1$ in the presence of $0-40 \mu \mathrm{g} / \mathrm{mL}$ heparin.

(D) Fitting of PSM $\beta 1$ kinetic data at $0.025 \mathrm{mg} / \mathrm{mL}$ PSM $\beta 1$ in the presence of $50-250 \mu \mathrm{g} / \mathrm{mL}$ heparin.

(E) Fitting of PSM $\beta 2$ kinetic data at $0.25 \mathrm{mg} / \mathrm{mL}$ PSM $\beta 2$ in the presence of $0.1-1 \mu \mathrm{g} / \mathrm{mL}$ heparin.

(F) Fitting of $\delta$-toxin kinetic data at $0.3 \mathrm{mg} / \mathrm{mL} \delta$-toxin in the presence of $0.2-0.8 \mu \mathrm{g} / \mathrm{mL}$ heparin fitted to a secondary nucleation dominated model using global constants: $\mathrm{n}_{\mathrm{c}}, \mathrm{n}_{2}, \mathrm{k}_{+} \mathrm{k}_{\mathrm{n}}$, individual fit: $\mathrm{k}_{+} \mathrm{k}_{2}$. 

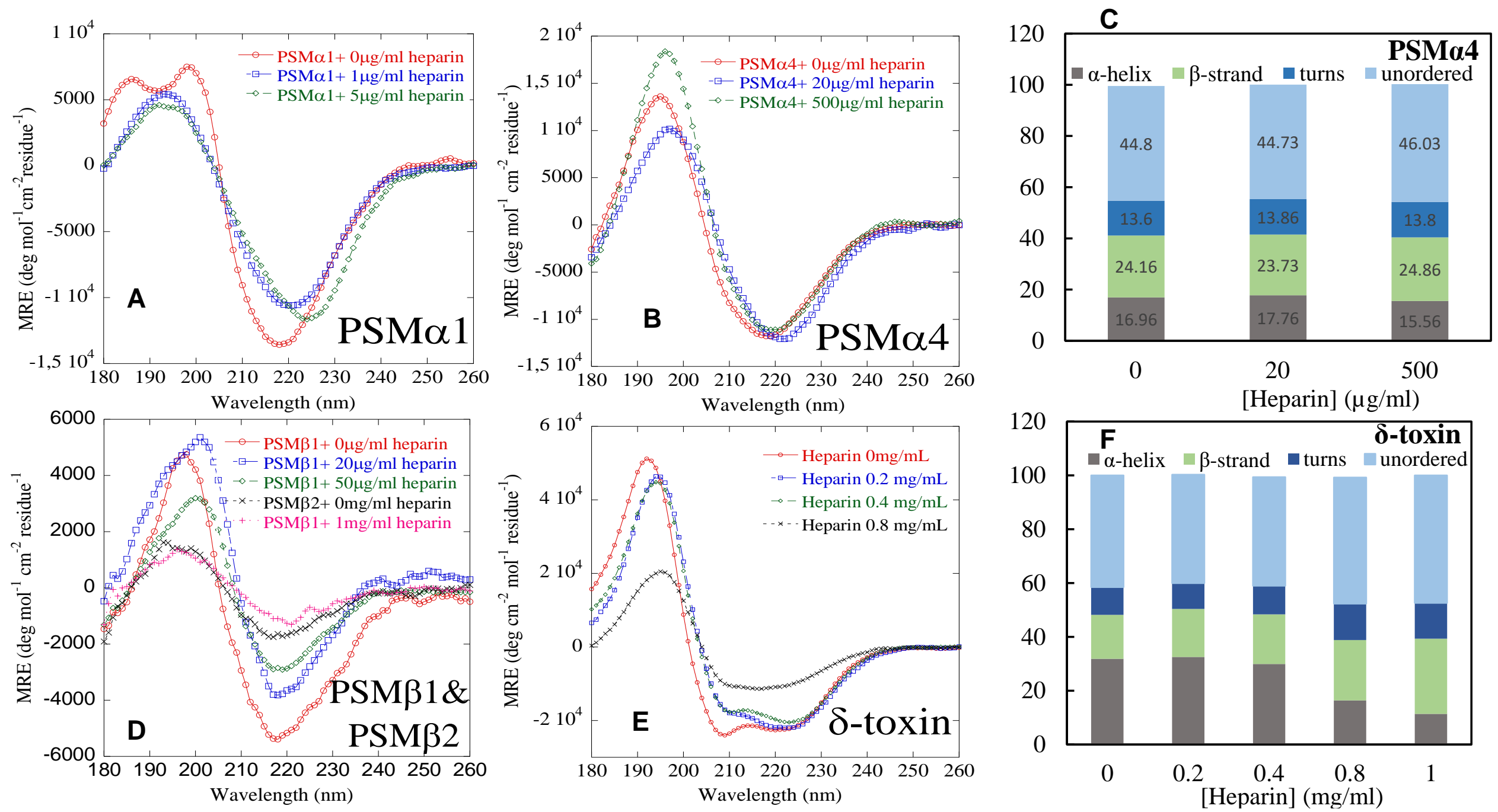

Figure S4: Conformational conversion of PSMs followed by far-UV CD. (A) SRCD spectra of PSM $\alpha 1$ ( $0.25 \mathrm{mg} / \mathrm{mL})$ in absence and presence of different concertation of heparin. (B) SRCD spectra of PSMa4 $(0.25 \mathrm{mg} / \mathrm{mL})$ in absence and presence of different concertation of heparin. (C) Deconvolution of the SRCD spectra of fibrils of PSM $\alpha 4$ (with/out heparin) into the individual structural components. (D) Synchrotron radiation (SR) Far UV-CD spectra of all $\beta$-group of PSMs fibrils incubated with/out heparin. (E) Synchrotron radiation (SR) Far UV-CD spectra of $\delta$-toxin fibrils incubated in absence and presence of different concentrations of heparin. (F) Deconvolution of the SRCD spectra of fibrils of $\delta$-toxin (with/out heparin) into the individual structural components. 


\section{Figure S6}
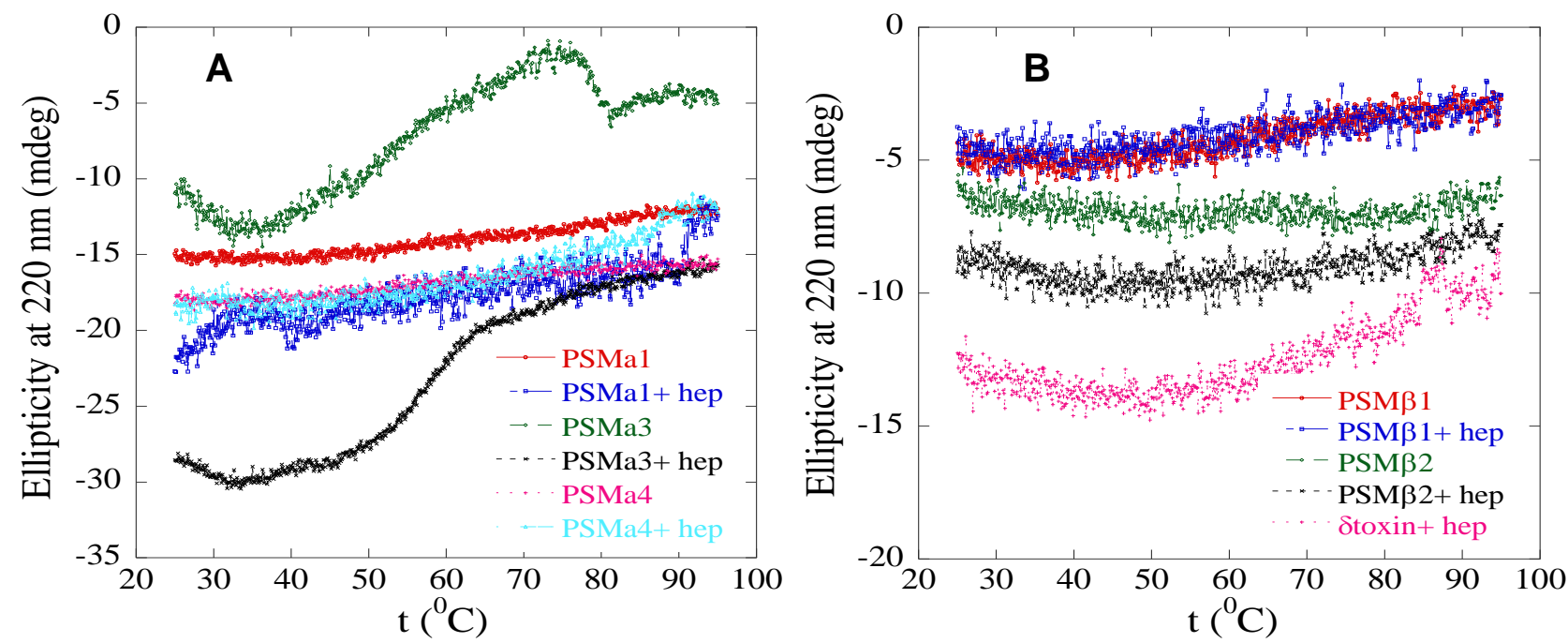

Figure S6: (A) CD thermal scans from 20 to $95^{\circ} \mathrm{C}$ of $\alpha$-PSM fibrils incubated in absence and presence of heparin. The concentration of heparin are $3 \mu \mathrm{g} / \mathrm{mL}$ for PSM $\alpha 1,40$ $\mu \mathrm{g} / \mathrm{mL}$ for PSM $\alpha 3,50 \mu \mathrm{g} / \mathrm{mL}$ for PSM $\alpha 4$, (B) CD thermal scans from 20 to $95^{\circ} \mathrm{C}$ of $\beta$ $\mathrm{PSM}$ and $\delta$-toxin fibrils incubated in absence and presence of heparin (Heparin concentrations: $250 \mu \mathrm{g} / \mathrm{mL}$ for PSM $\beta 1,1 \mathrm{mg} / \mathrm{mL}$ for PSM $\beta 2$ and $1 \mathrm{mg} / \mathrm{mL}$ for $\delta$-toxin). 


\section{Figure S7}

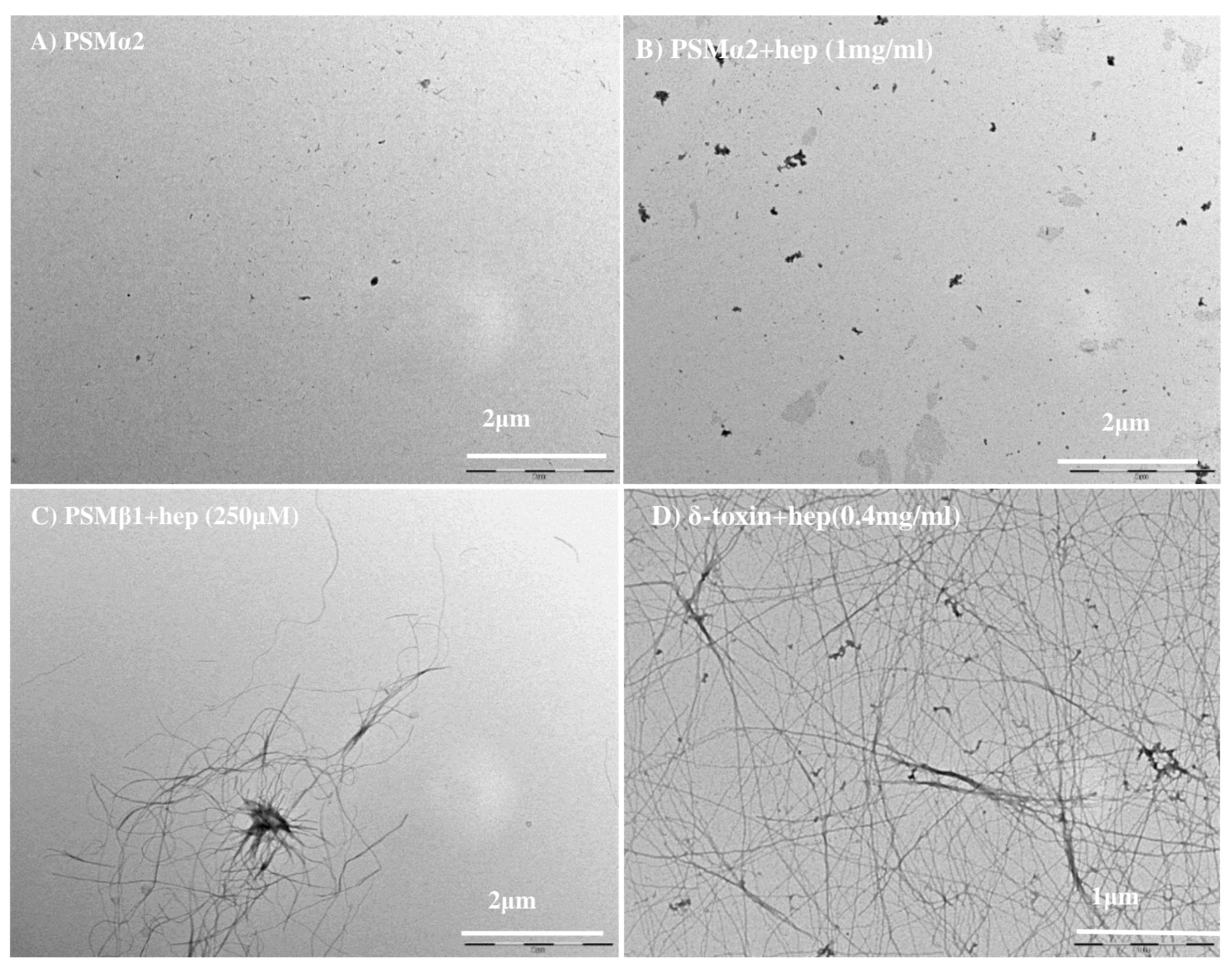

Figure S7: TEM images of PSM fibrils with and without heparin. (a) PSM $\alpha 2$ without heparin, (b) PSM $\alpha 2$ with $1 \mathrm{mg} / \mathrm{mL}$ heparin, (c) PSM $\beta 1$ with $250 \mu \mathrm{g} / \mathrm{mL}$ heparin and (d) $\delta$-toxin with 0.4 $\mathrm{mg} / \mathrm{mL}$ heparin. Note that scale bar changes. 

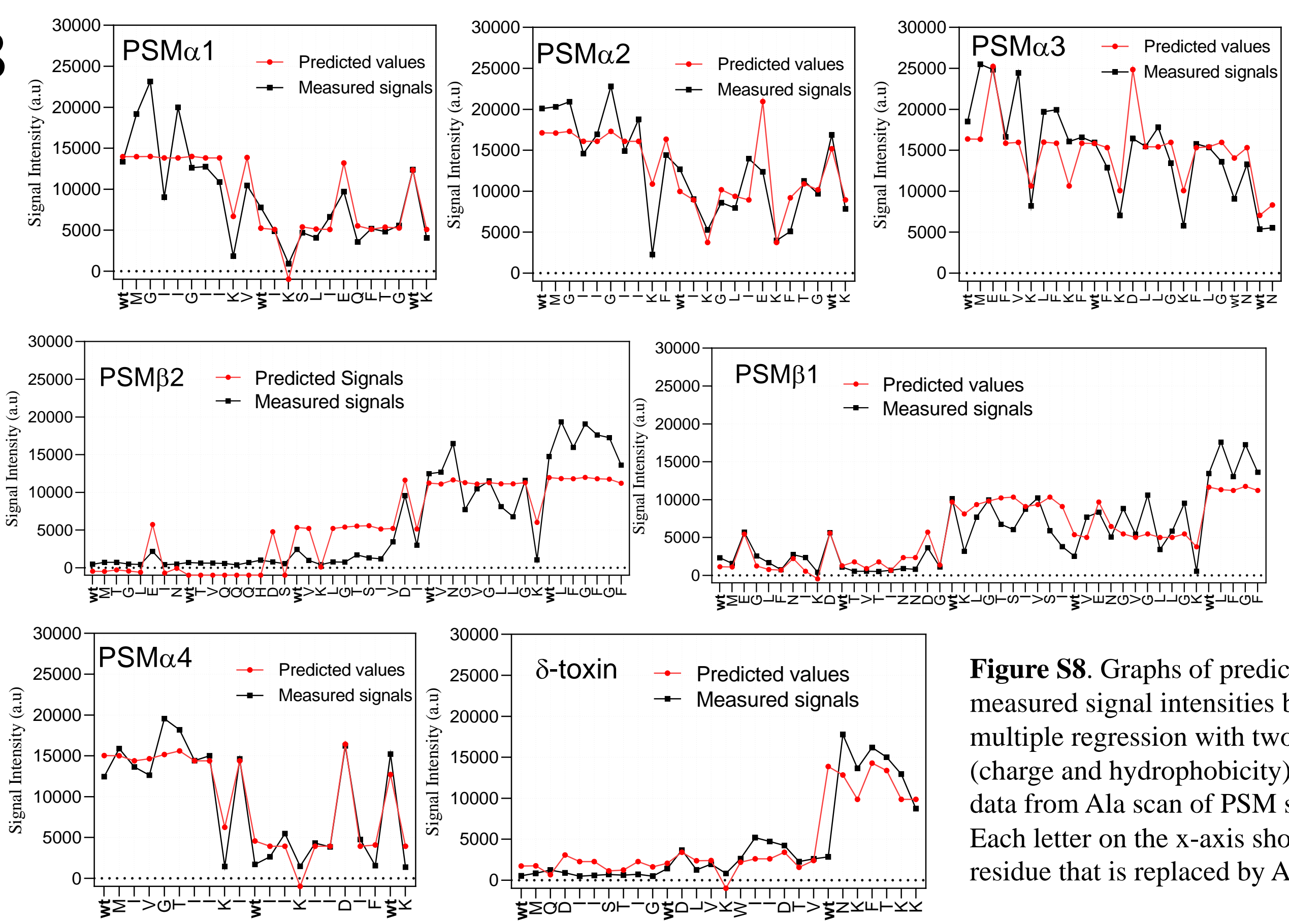

Figure S8. Graphs of predicted and measured signal intensities based on multiple regression with two variables (charge and hydrophobicity) based on data from Ala scan of PSM sequences. Each letter on the $\mathrm{x}$-axis shows the residue that is replaced by Ala. 


\section{Table S1}

Table S1. Composite rate constant $\left(k_{+} k_{n}\right.$ in units of conc ${ }^{-n-1}$ time $\left.^{-2}\right)$ of secondary nucleation model from fitting of ThT-data with Amylofit web server.

\begin{tabular}{|c|c|c|c|c|c|c|c|c|c|c|}
\hline \multicolumn{2}{|c|}{$\begin{array}{c}\text { Heparin } \\
\mu \mathrm{g} / \mathrm{ml}\end{array}$} & PSMa1 & Heparin & PSMa3 & Heparin & PSM $\beta 1$ & $\begin{array}{c}\text { Heparin } \\
\mu \mathrm{g} / \mathrm{ml}\end{array}$ & PSM $\beta 1$ & $\begin{array}{c}\text { Heparin } \\
\mu \mathrm{g} / \mathrm{m}\end{array}$ & PSM 32 \\
\hline \multirow{7}{*}{ 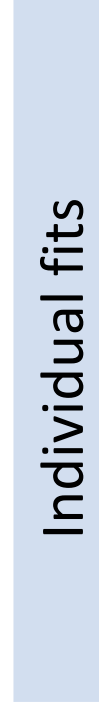 } & 0 & $6.84 \times 10^{-10}$ & 0 & 536 & 0 & $3.57 \times 10^{+17}$ & 50 & $1.52 \times 10^{+12}$ & 0 & 362.00 \\
\hline & 0.5 & $1.19 \times 10^{-8}$ & 10 & 900 & 5 & $2.78 \times 10^{+17}$ & 75 & $3.66 \times 10^{+10}$ & 0.1 & 20.00 \\
\hline & 1 & $1.22 \times 10^{-7}$ & 20 & $1.30 \times 10^{+3}$ & 10 & $2.64 \times 10^{+17}$ & 100 & $5.04 \times 10^{+7}$ & 0.15 & 10.60 \\
\hline & 1.5 & $4.43 \times 10^{-6}$ & 25 & $1.75 \times 10^{+3}$ & 20 & $4.66 \times 10^{+17}$ & 150 & $4.09 \times 10^{+3}$ & 0.2 & 9.55 \\
\hline & 2 & $1.63 \times 10^{-4}$ & 30 & $2.64 \times 10^{+3}$ & 30 & $1.19 \times 10^{+18}$ & 200 & $1.57 \times 10^{+5}$ & 0.25 & 6.55 \\
\hline & 3 & $1.32 \times 10^{-3}$ & 40 & $3.75 \times 10^{+3}$ & 40 & $1.87 \times 10^{+18}$ & 250 & $1.32 \times 10^{+4}$ & 0.5 & 0.87 \\
\hline & & - & & & & & & - & 1 & 0.53 \\
\hline $\begin{array}{l}\frac{n}{ \pm} \\
\frac{\stackrel{0}{\pi}}{0} \\
\frac{0}{0} \\
\end{array}$ & \multicolumn{2}{|c|}{$\begin{array}{l}\mathrm{m}_{0}=110 \mu \mathrm{M} \\
\mathrm{n}_{\mathrm{c}}=1.98 \times 10^{-5} \\
k_{+} k_{2}=2.63 \times 10^{+5} \\
\left(\text { conc }^{-\mathrm{n} 2-1} \text { time }^{-2} \text { ) }\right. \\
\mathrm{n}_{2}=0.542 \\
\text { MRE:0.00488 }\end{array}$} & \multicolumn{2}{|c|}{$\begin{array}{l}\mathrm{m}_{0}=96 \mu \mathrm{M} \\
\mathrm{n}_{\mathrm{c}}=0.723 \\
k_{+} k_{2}=1.57 \times 10^{+8} \\
\left(\text { conc }^{-\mathrm{n} 2-1} \text { time }^{-2}\right) \\
\mathrm{n}_{2}=0.695 \\
\text { MRE:0.00176 }\end{array}$} & \multicolumn{2}{|c|}{$\begin{array}{l}\mathrm{m}_{0}=55 \mu \mathrm{M} \\
\mathrm{n}_{\mathrm{c}}=4 \\
k_{+} k_{2}=2.38 \times 10^{+4} \\
\left(\text { conc }^{-\mathrm{n} 2-1} \text { time }^{-2}\right) \\
\mathrm{n}_{2}=0.316 \\
\text { MRE:0.00418 }\end{array}$} & \multicolumn{2}{|c|}{$\begin{array}{l}\mathrm{m}_{0}=55 \mu \mathrm{M} \\
\mathrm{n}_{\mathrm{c}}=3.92 \\
k_{+} k_{2}=6.71 \times 10^{+5} \\
\left(\text { conc }^{-\mathrm{n} 2-1} \text { time }^{-2}\right) \\
\mathrm{n}_{2}=0.2 \\
\text { MRE:0.00905 }\end{array}$} & \multicolumn{2}{|c|}{$\begin{array}{l}\mathrm{m}_{0}=5.61 \mu \mathrm{M} \\
\mathrm{n}_{\mathrm{c}}=0.762 \\
k_{+} k_{2}=3.05 \times 10^{+4} \\
\left(\text { conc }^{-\mathrm{n} 2-1} \text { time }^{-2} \text { ) }\right. \\
\mathrm{n}_{2}=0.00378 \\
\text { MRE: } 0.0117\end{array}$} \\
\hline
\end{tabular}

